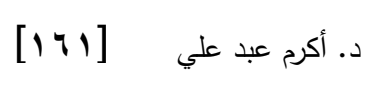

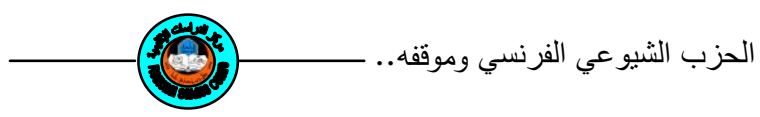

$$
\text { الحزب الثيوعي الفرنسي }
$$

وموقفه من بعض القضايا العربية المعاصرة

$$
\text { أستاذ مساعد / قسم التاريخ / كلية التربية / جامعة الموصل على علد }
$$

مستخلص البحث

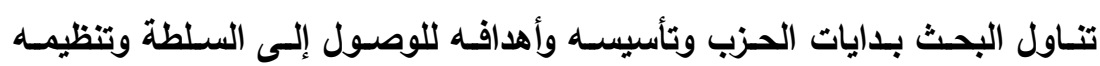

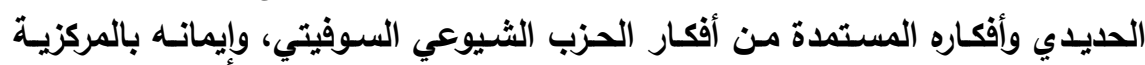

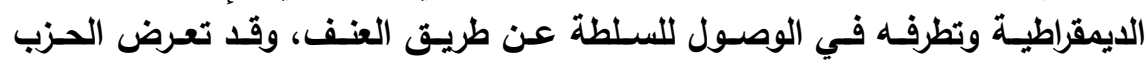

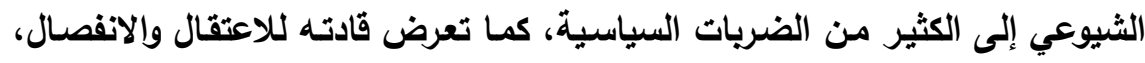

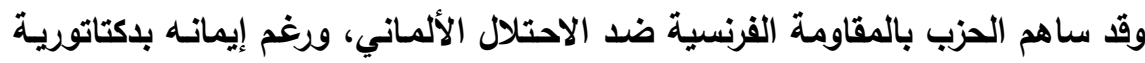

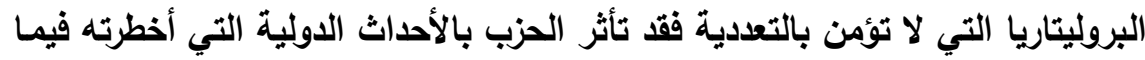

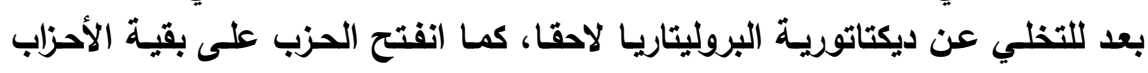

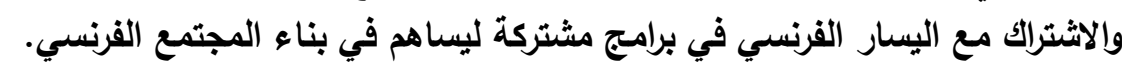

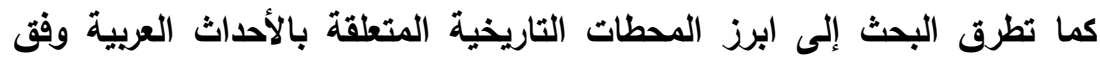

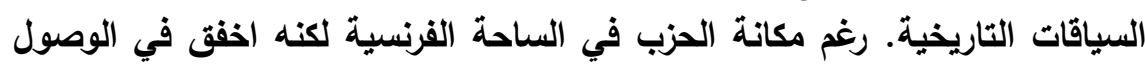
للسلطة لان بقية الأحزاب تتوحد لتعيق استلامه السلطة في فرنسا.

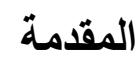

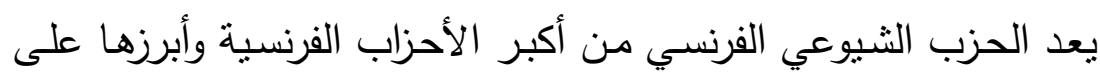

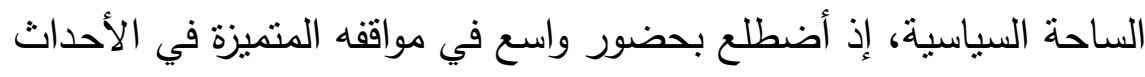

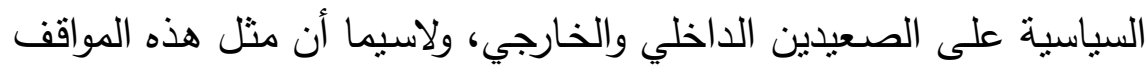

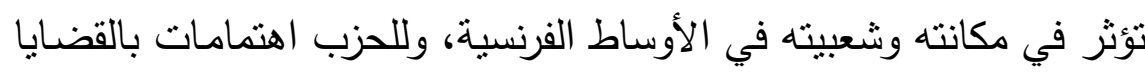
العربية ومواقف متذبذبة منها. 
وعلى الرغم من وجود بعض الكتابات حول هذا الحزب، لكنها سريعة في

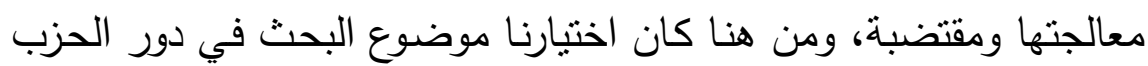

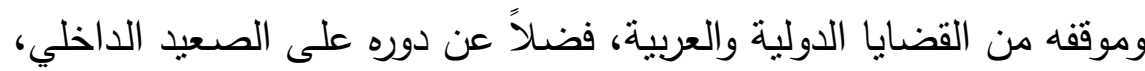
بغية الخروج بثيء مفيد من خلال مواقف هذا الحنبة الحزب.

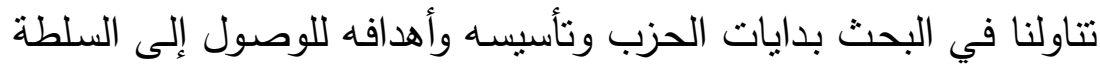

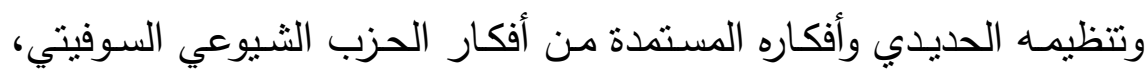

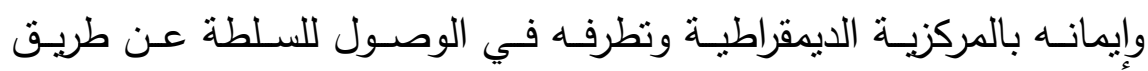

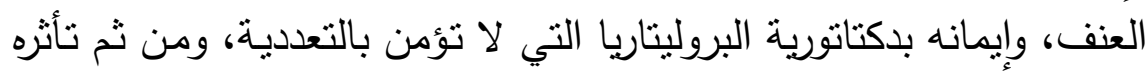

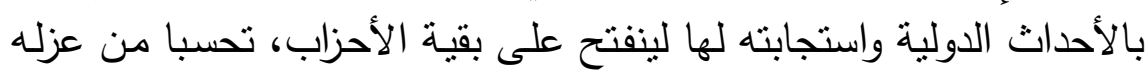

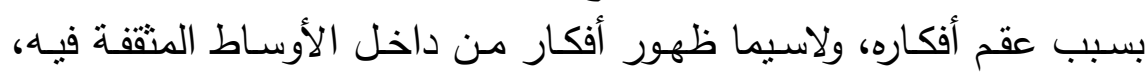

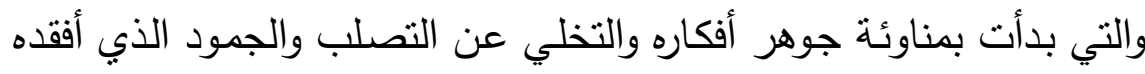

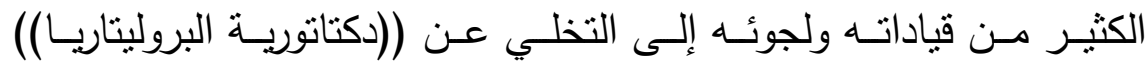

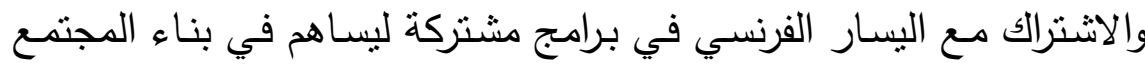

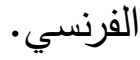
ينقسم البحث فضـلا عن المقدمة والخاتمـة إلى محورين، أولهما بتطرق

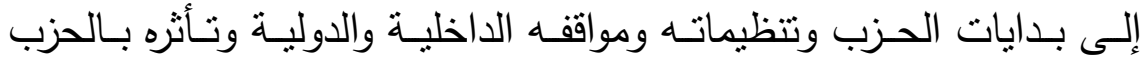

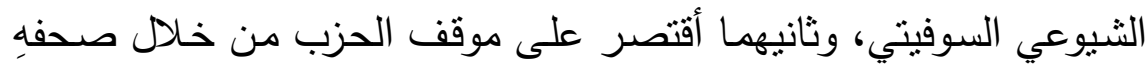
إزاء أبرز المحطات التاريخية المتعلقة بالأحداث العربية على وفق التهن السياقات التاريخية لهذه الأحداث البارزة.

\section{المحور الأول: نثأة الحزب الثيوعي الفرنسي}

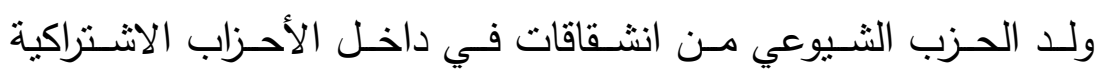

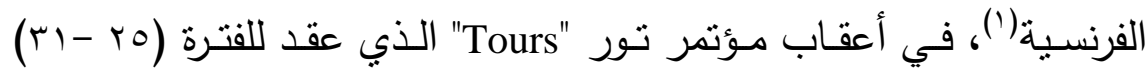

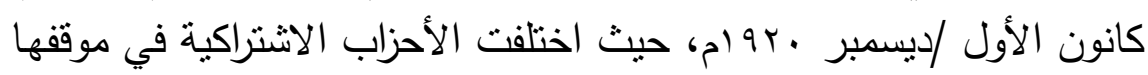

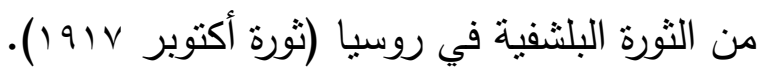


د. أكرم عبد علي [ [ [14]

فقــــوافقـت الأغليــة مـن الاثـتراكيين الفرنسـيين على شـروط الحـزب

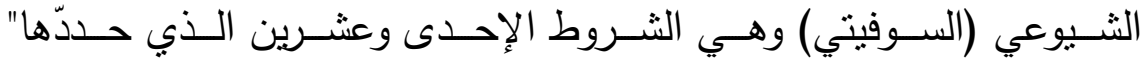

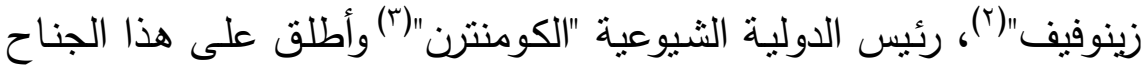

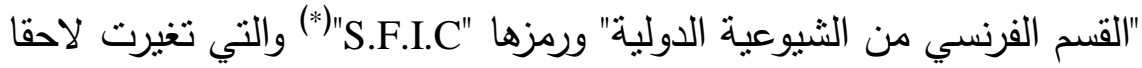
إلى الحزب الثيوعي الفرنسي "P.C.F" في حين كونت الأقلية الاثتراكية الجناح الفرنسي للعمالية الدولية ورمزها

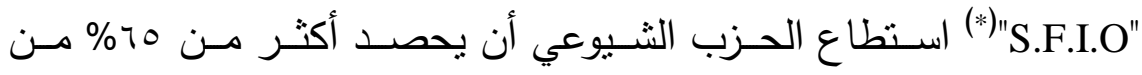

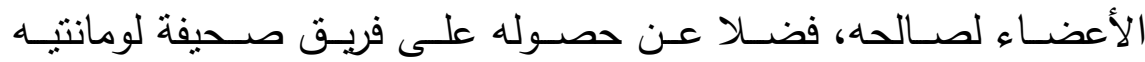

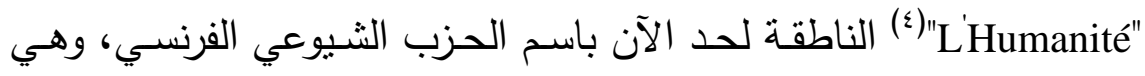

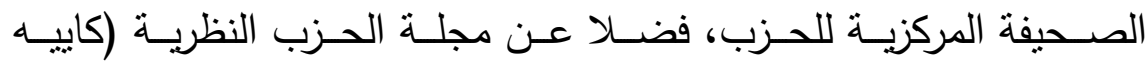

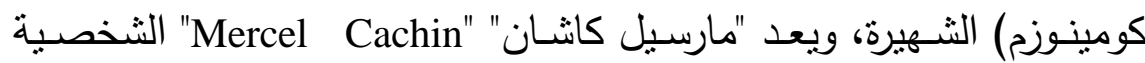
العمالية أول رئيس تحرير لصحيفة لومانتيه حتى وفاته عام . ب9 أ.

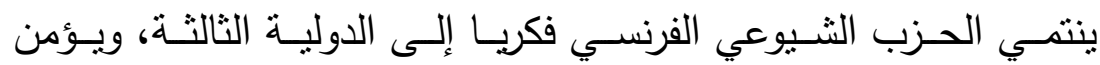

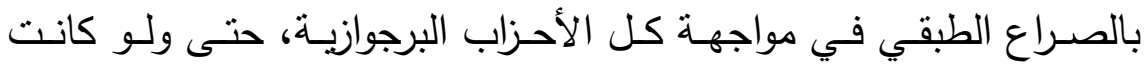

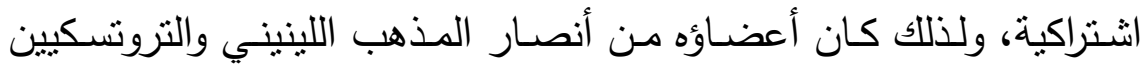

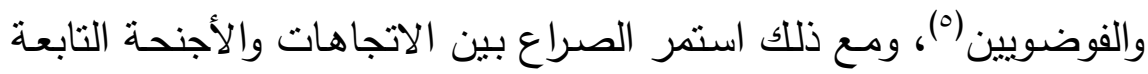

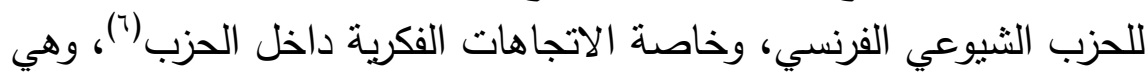
انعكاسات للخلافات الثيوعية التي برزت في تيارات ((روسمير، سوفارين، والتروتسكيين)) فضلا عن الصراعات الثخصية(V) قام الحزب الثـيوعي الفرنسي على الأسس التظظيميـة للحزب الثبيوعي السوفيتي نفسها، كالعلاقات الرأسية بين الوحدات، فضـلا عن إيمانه بفكرة المركزية الديمقراطية. 
أما انتخاب أعضاء الحزب، فيتم من خلال الهيئات التي هي أدنى منها،

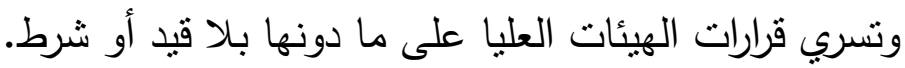

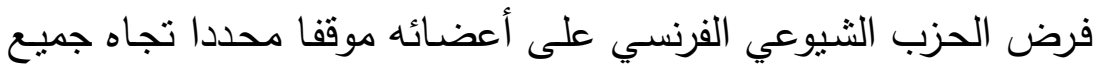

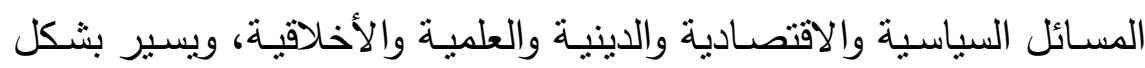
أمين على خطوات الحزب الثشيوعي السوفيتي، بل ويعد من أكثر الأحزاب ولاءً

يتـألف المكتب السياسـي للحزب، مـن حـوالي عشـرين عضــــا أساسـيا

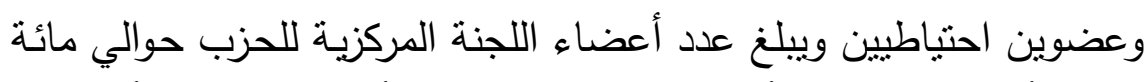

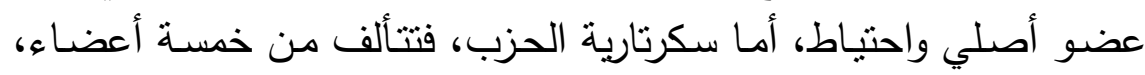

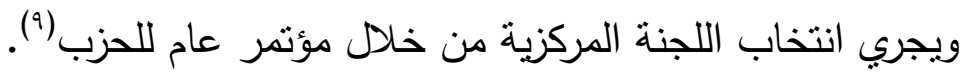

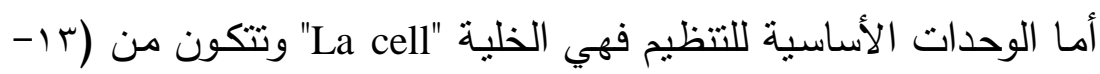

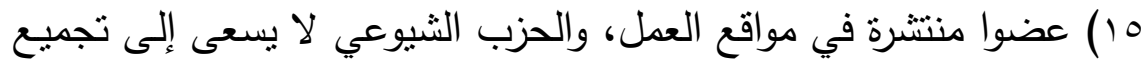

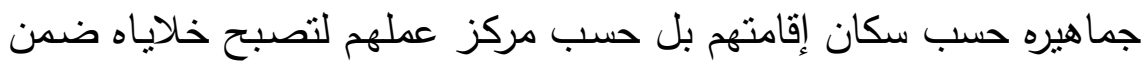

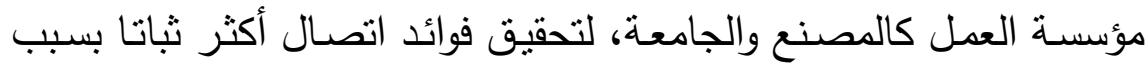

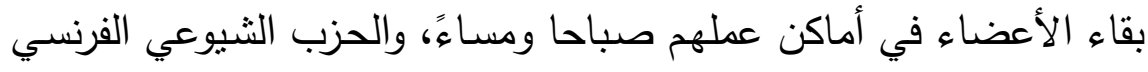

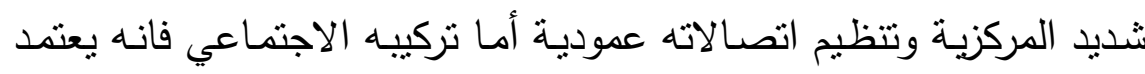
على الطبقة العاملة والطليعة المتقدمة للبروليتاريا أما فلسفة العقيدة الثيوعية التئية

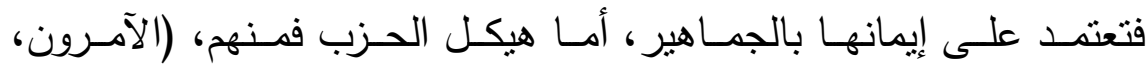

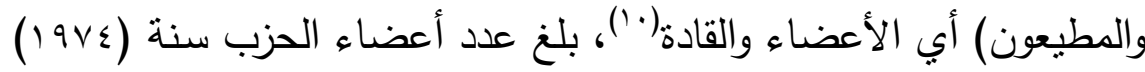
حوالي .0؛ ألف عضوا، ويصوت للحزب نسبة النساء أكثر من الرجال وفئة التهاء الثباب تتجاوز فئة الكهول("'). يعد "جوليس جوسيد J.Guesde" أبرز القادة الثيوعيين الذين امنوا بالفكر

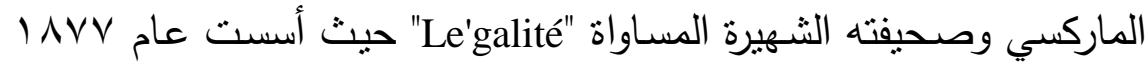




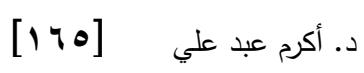

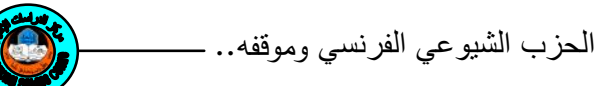

م حيث استمدت تسميتها من إحدى شعارات الثورة الفرنسية ولائحة حقوق

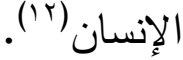

وقد أسس "جوسيد"(') مع زميله "بول لافارج P.Lafargue " ذي الجي الجذور

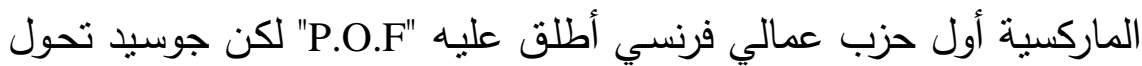

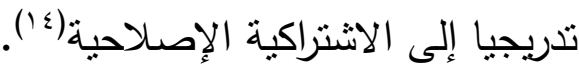

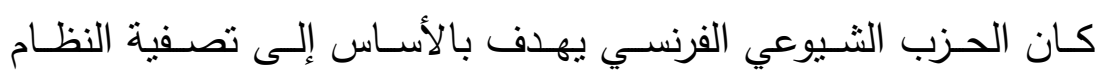

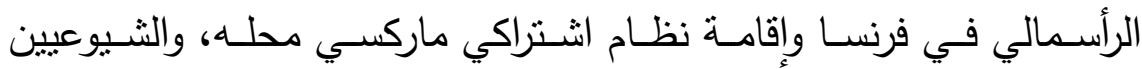

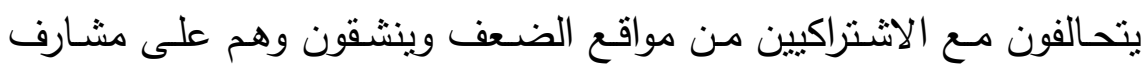
القوة:10).

أسس الحزب الثيوعي الفرنسي بعد الانثطار في أعقاب مؤتنر ليل،

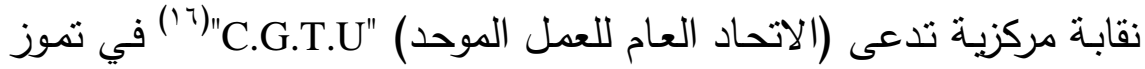

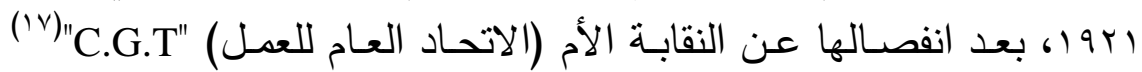

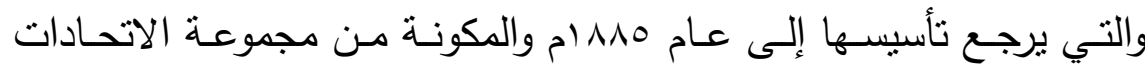

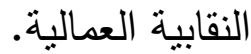

ومن أبرز أعضـاء الحزب الثنيوعي، رئيس الاتحساد العـام للعمال بنو

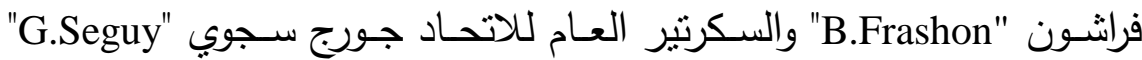

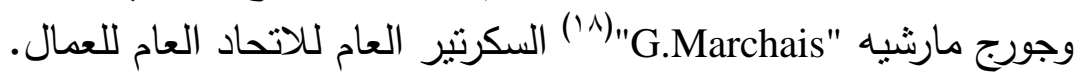

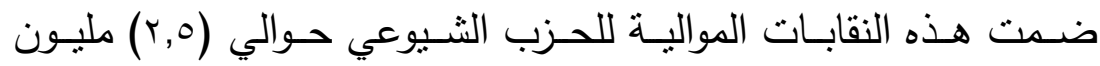

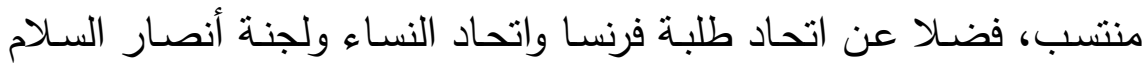
ورابطة المحاربين القدماء(19).

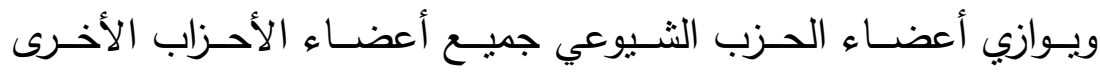

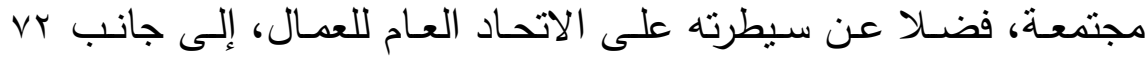

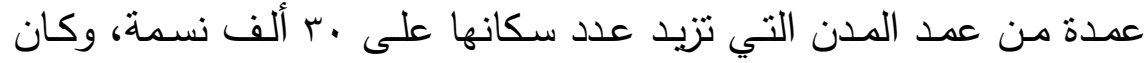

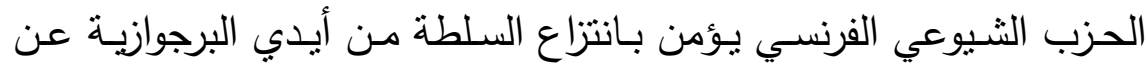


طريق العنف، وبكل الطرق سواء المشروعة أو غير الششروعة بدليل تأييده

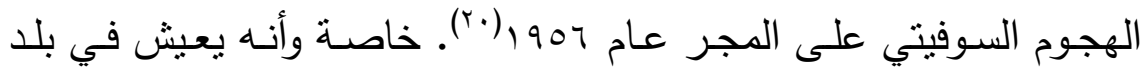

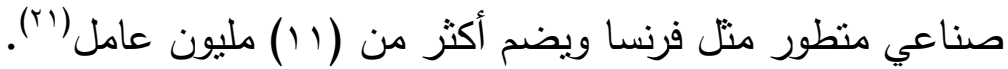

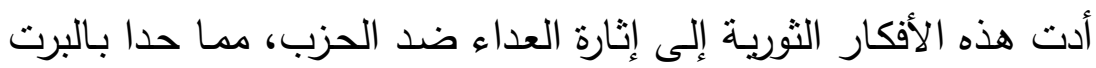

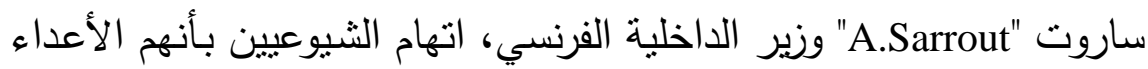

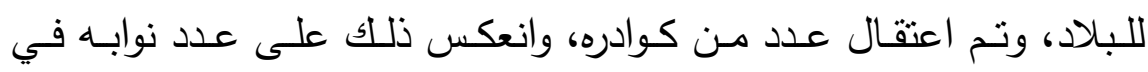
الجمعية الوطنيـة، في الوقت الذي غـادرت الكثير من القيادات الثشيوعية

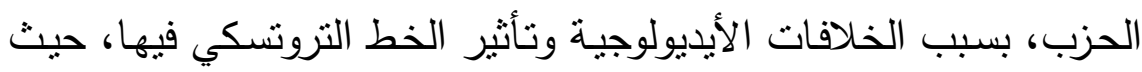

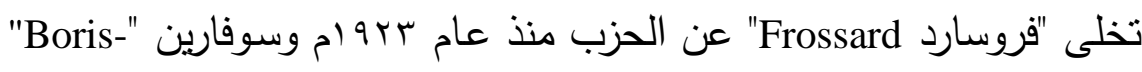

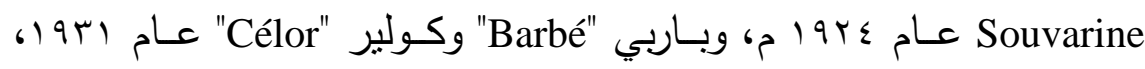

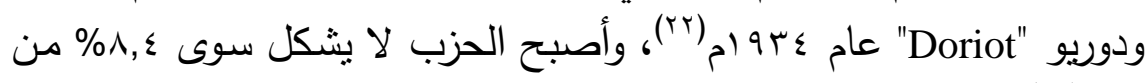
وزنه (rr)

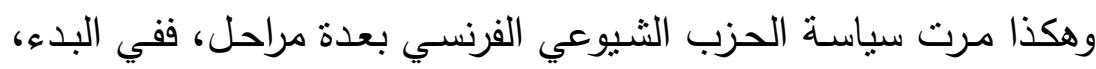

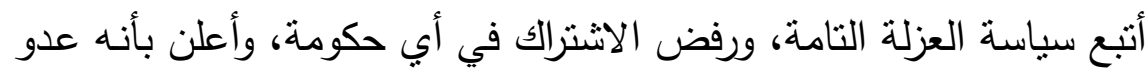

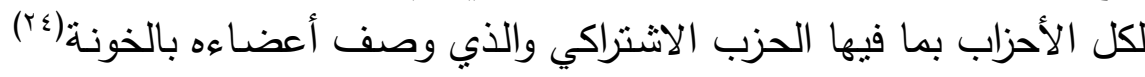

إن الأهداف الدولية للحزب الثنيوعي الفرنسي وارتباطه بالحزب الثنيوعي

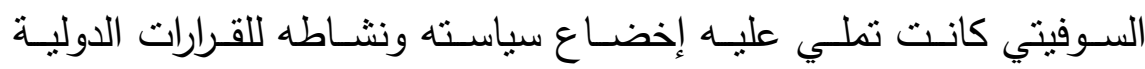
البروليتارية، ولو كان على حساب الأهداف الوطنية:(ro).

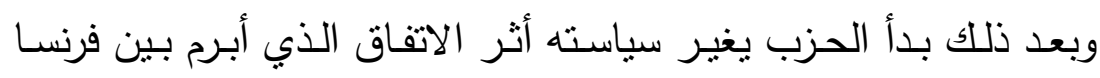

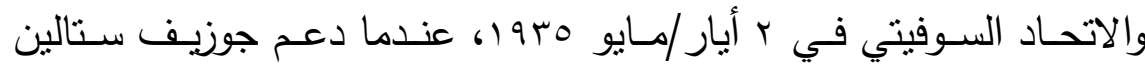

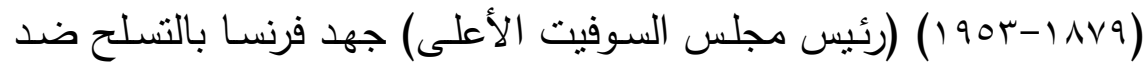

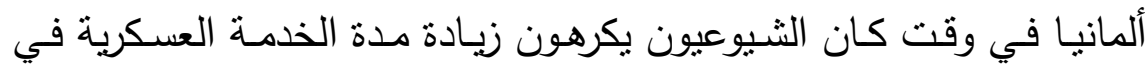
فرنسا والميزانية العسكرية. 
وإلا أن الموقف الذي اتخذه ستالين كان من شأنه أن يدفع شيوعيّي فرنسا

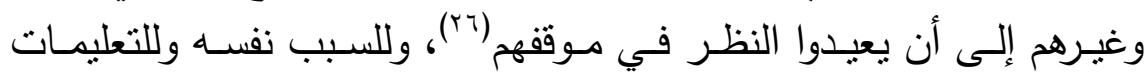

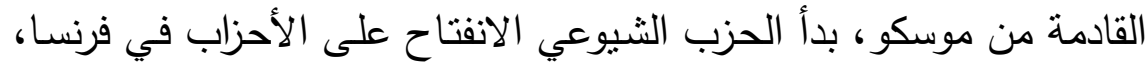

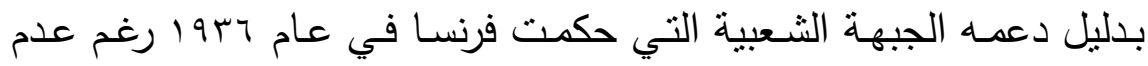
مشاركته فيها (rV وقد أكد الحزب الثشيوعي حضوره في السـاحة الفرنسية بقيادة "موريس

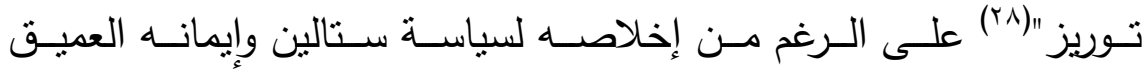
بالماركسية التي يقودها الاتحاد السوفيتي.

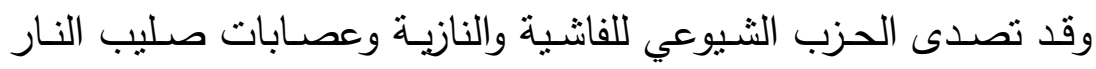

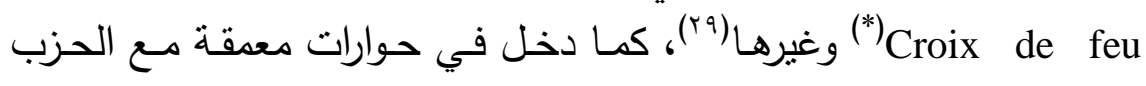

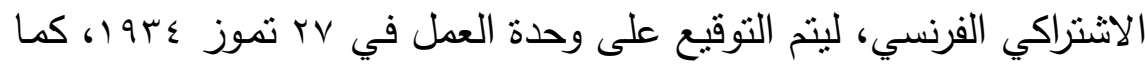

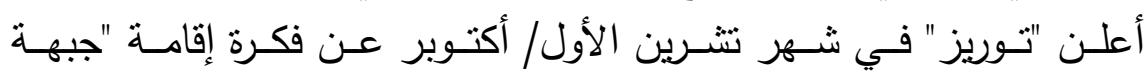

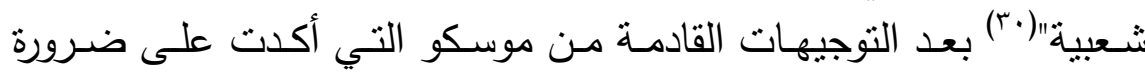

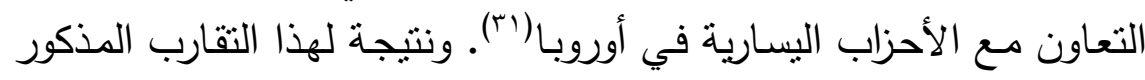

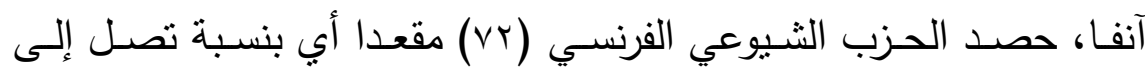

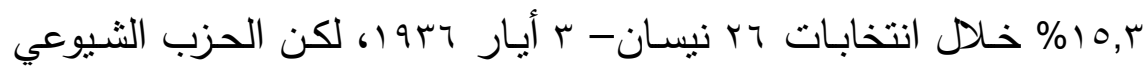

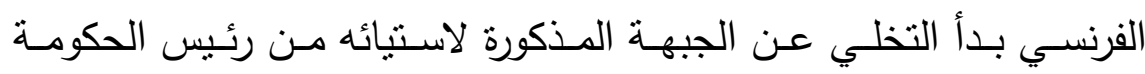

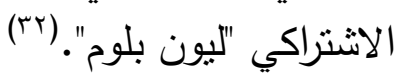

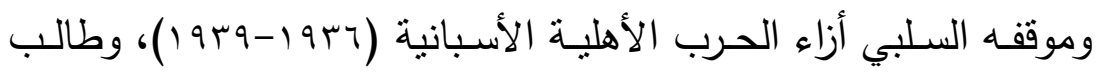

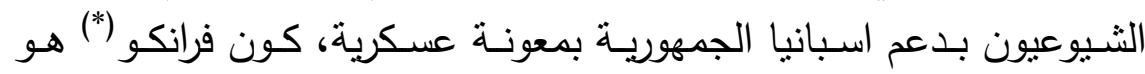

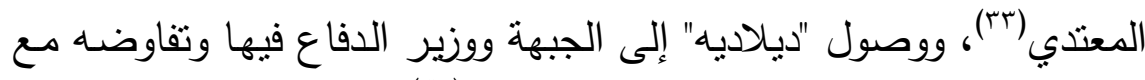

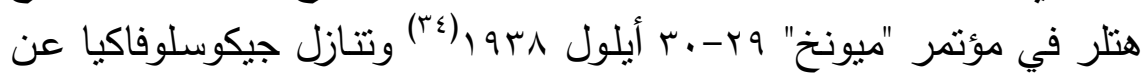

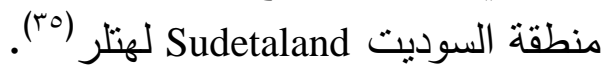


كما لعب الحزب الثيوعي دورا مهما في إنهاء الإضرابات التي عصفت

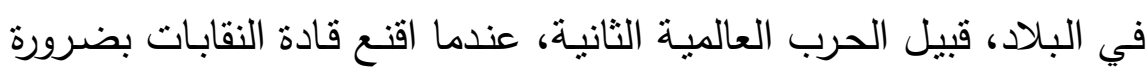

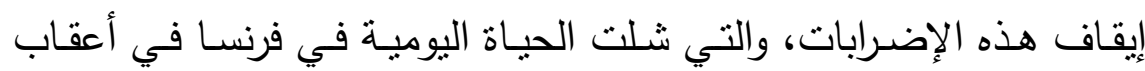

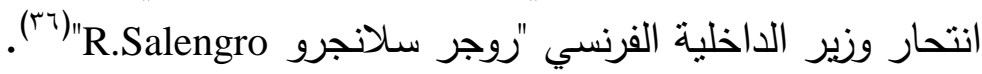

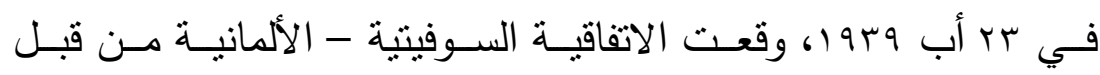

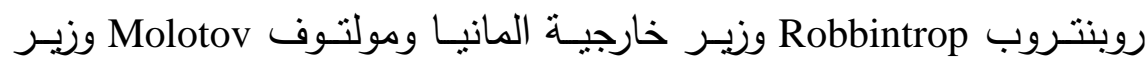

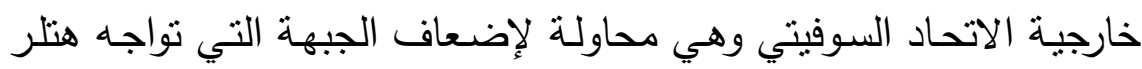

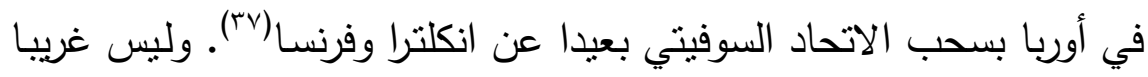

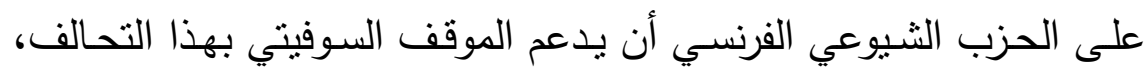

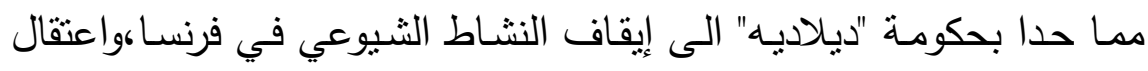

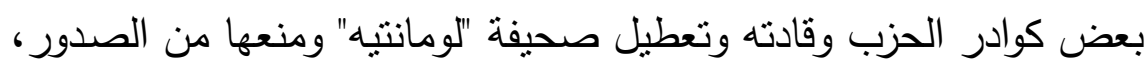

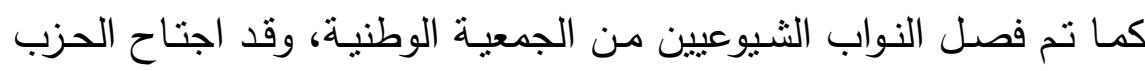

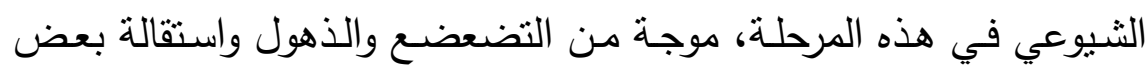

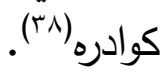
وخلال الحرب العالمية الثانية، تطور موقف الحزب الثيوعي ليأخذ موقفا

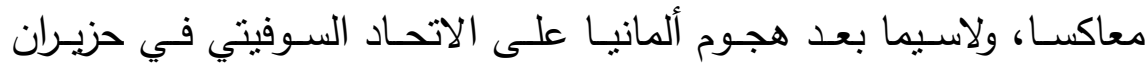

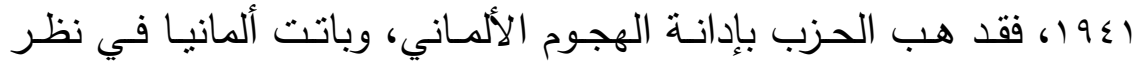

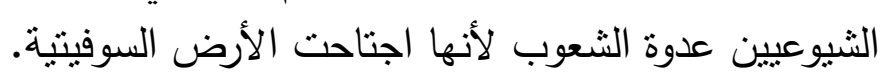

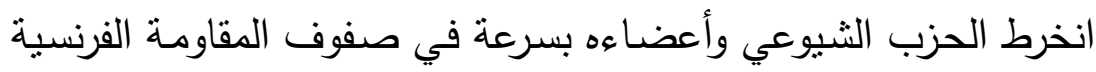
"C.N.R"

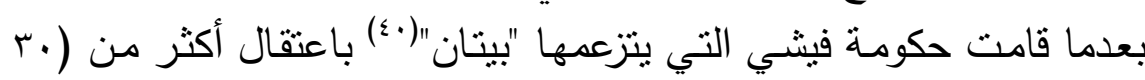

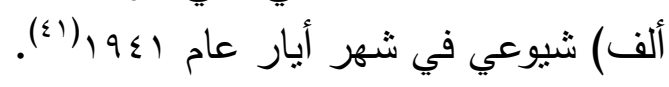

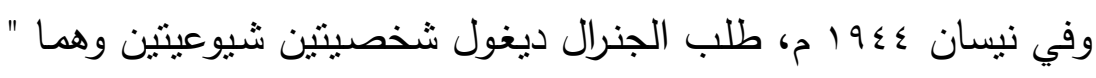

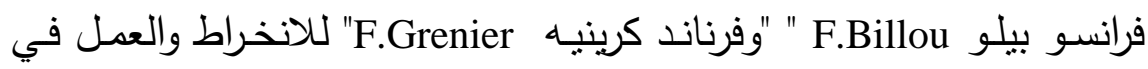




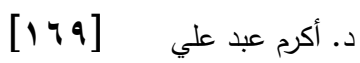

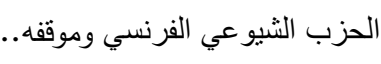

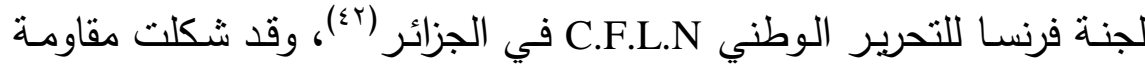

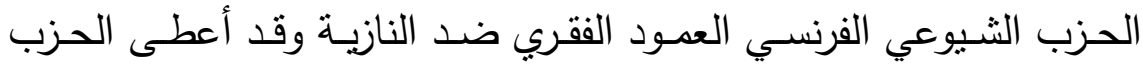

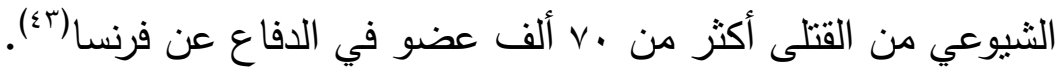

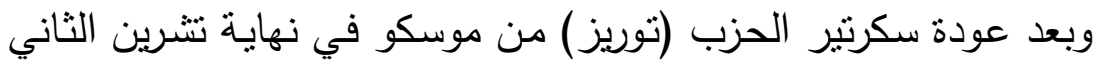

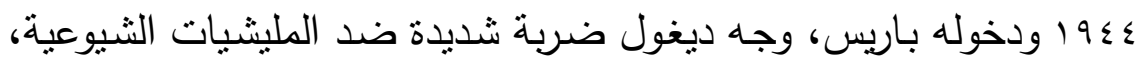

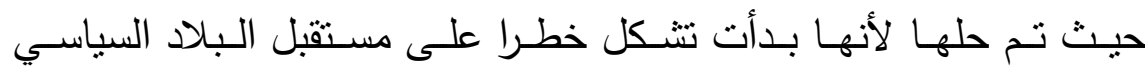

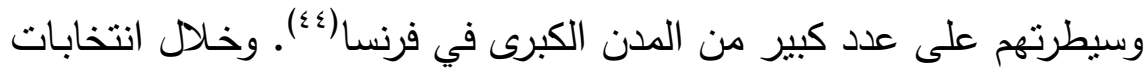

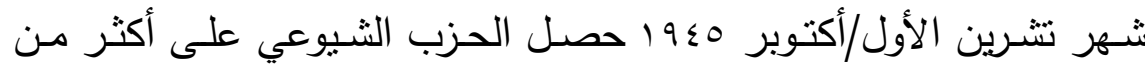

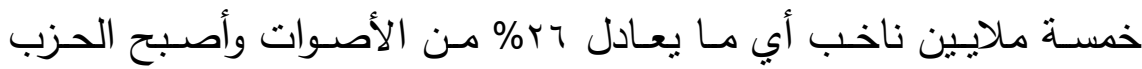

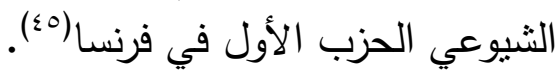

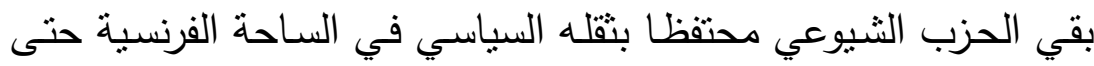

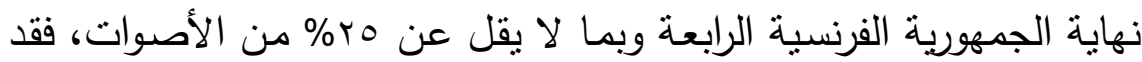

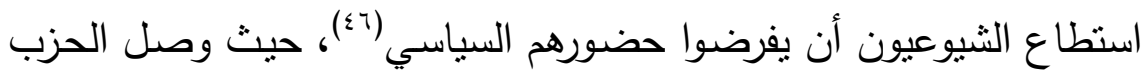

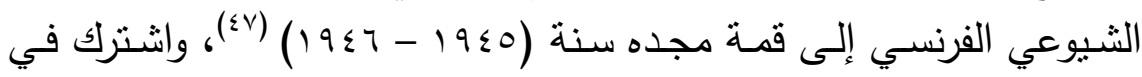
حكومة الجنرال ديغول الأولى بعد التحرير ، عندما تحالف مع الاثتنراكيين

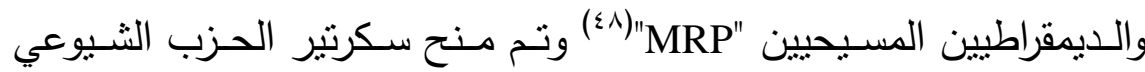

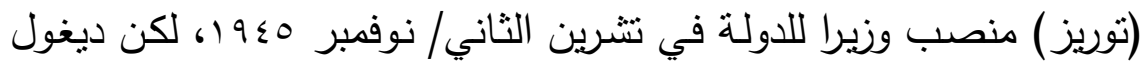

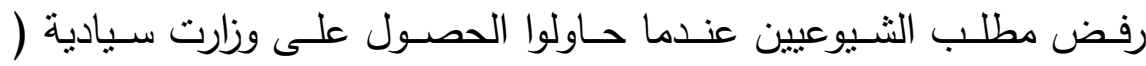
الافاع- الداخلية- الخارجية ).

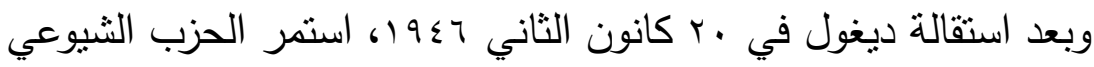

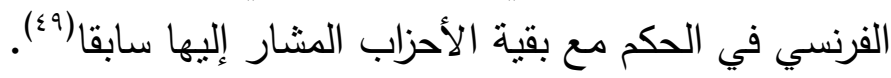

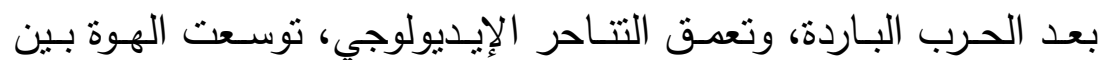

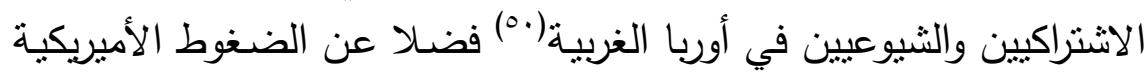
والصراع بين الثرق والغرب، وإدانة الوزراء الثشيوعيين والنواب خطة مارشال النشال 
plan Marshalle" الثيوعيون المجهودات العسكرية في حرب الهند الصينية (7 9 (19-190)، وأسـهم الشيوعيون في دعم الإضـرابات لعمال مصـانع "رينو " للسيارات في هي نيسان

وكـان رد فعـل رئيس الحكومـة "بـول راماديـه" الاشـتراكي أن قـام بابعـاد

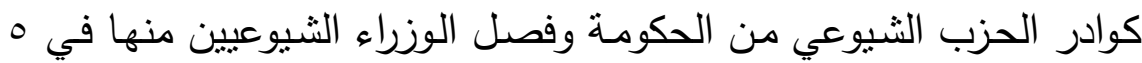

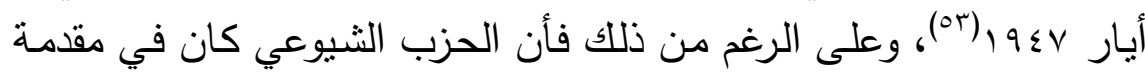

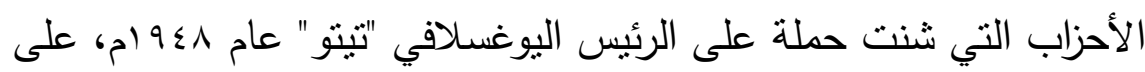
الرغم من رفض بعض الثيوعيين إدانة تيتو منل "جان كاسو" وفيركور ، كما

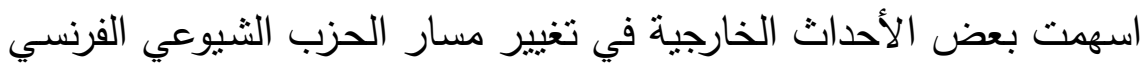

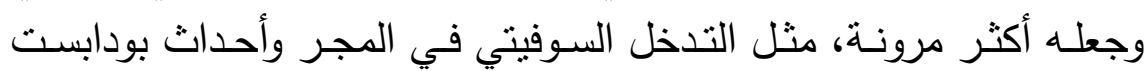

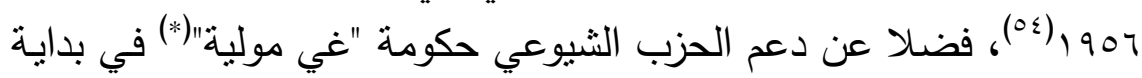

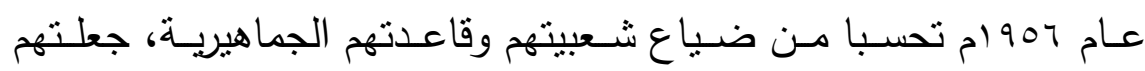
مضطرين للمشاركة مع الحكومة المذكورة آنفا(00).

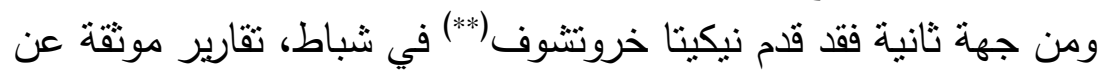

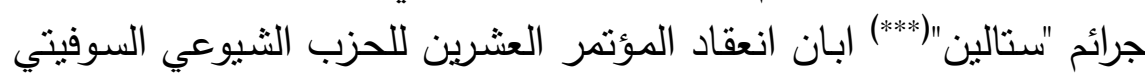
عندما تم إدانة الحقبة الستالينية(107).

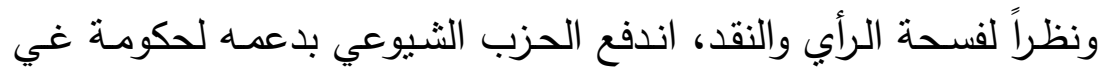

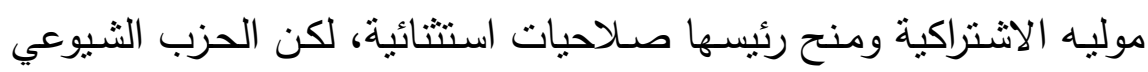

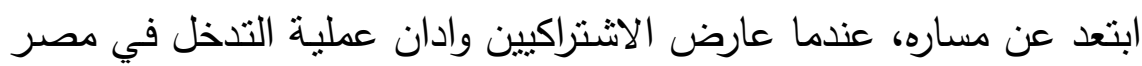

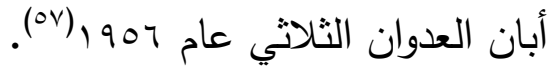

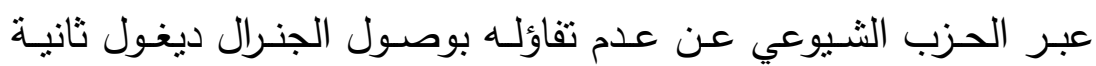

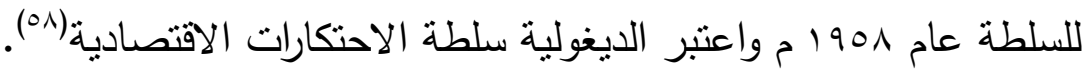




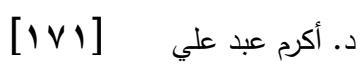

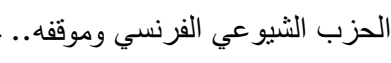

وبعد وفاة "توريز" سكرتير الحزب الثيوعي، نولى فالديك روشيه مسؤولية

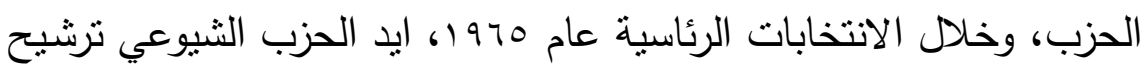

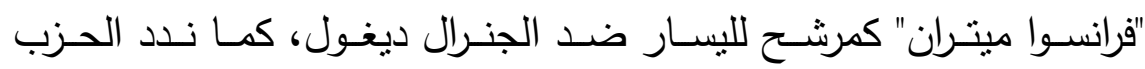

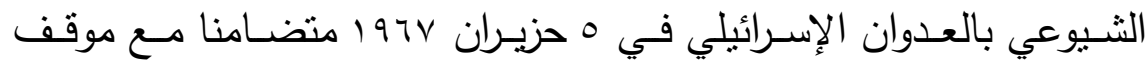

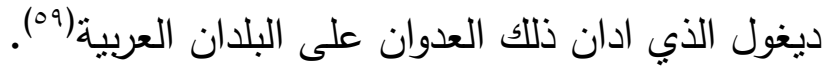

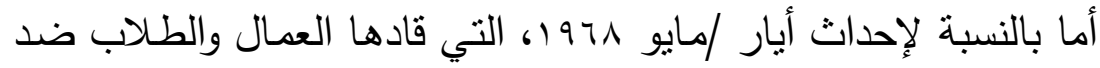

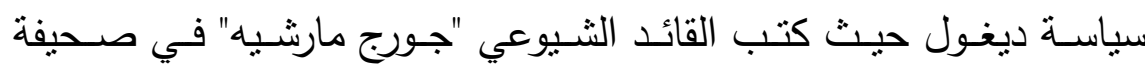

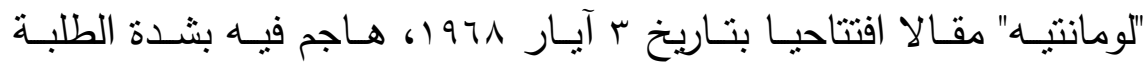

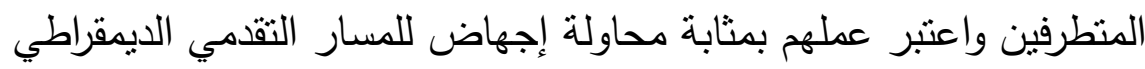

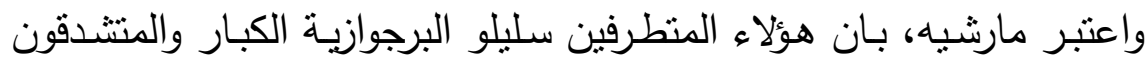

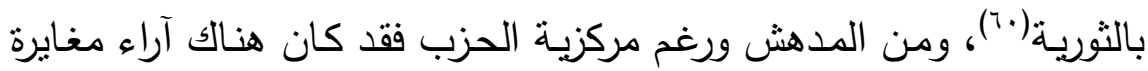

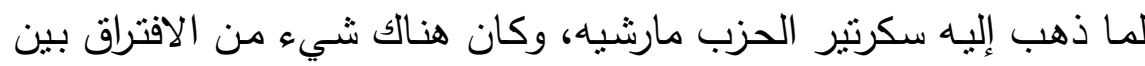

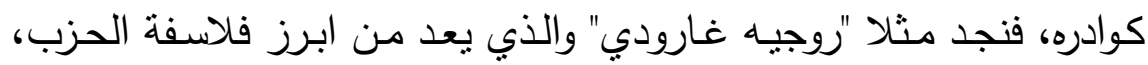

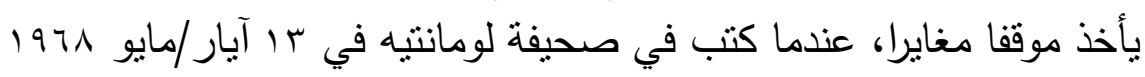

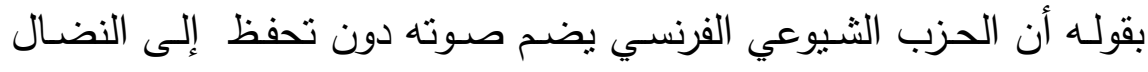

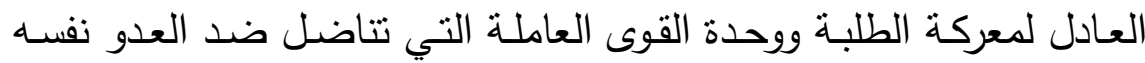

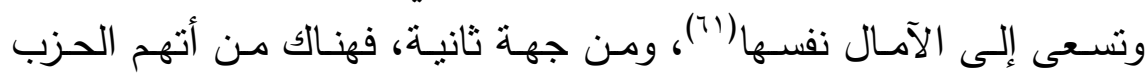

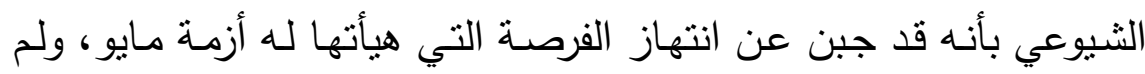

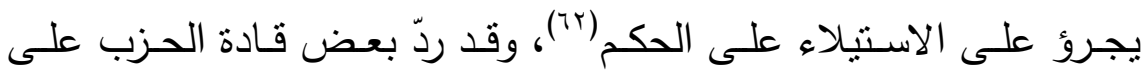

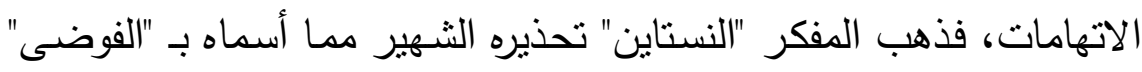

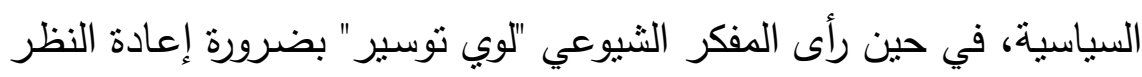

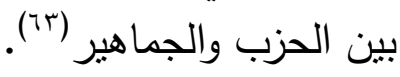

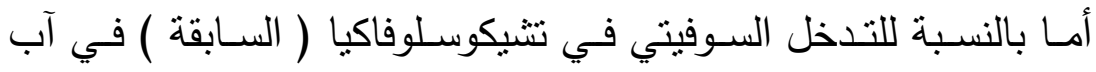
1971، عندما احتلت الجيوش السوفيتية وقوات حلف وارشو هذا البلد لمنع 
تشييد اشتراكية ديمقراطية، فقد عبر سكرتير الحزب "مارشية" عن موقف

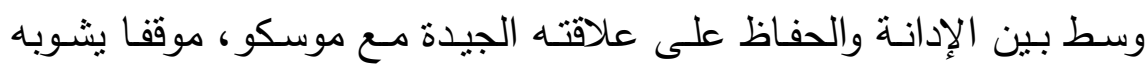

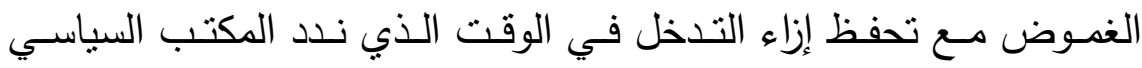

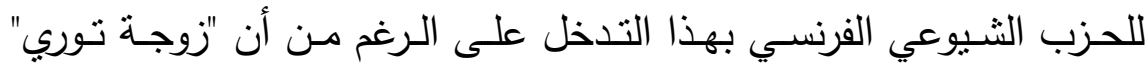

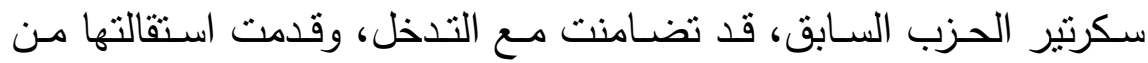

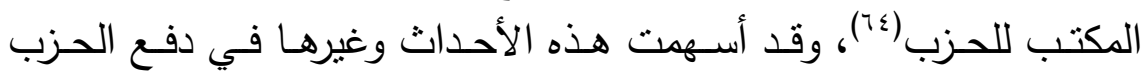

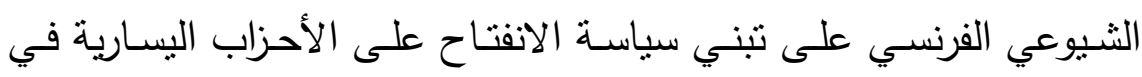

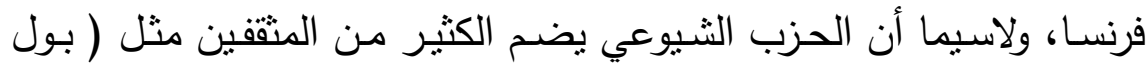

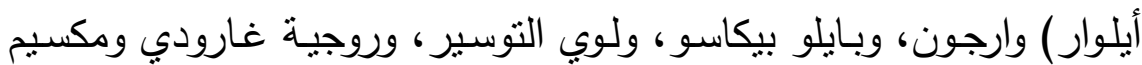
رودنسون (ro).

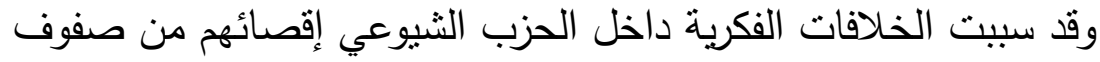
الحزب، فالمفكر الفرنسي روجيه غارودي تم إقصاؤه بسبب انتقاده التدخل السوفيتي ووقوفه على جانب" الحركة الإصـلاحية لربيع بـراغ" (") وقد انتقد

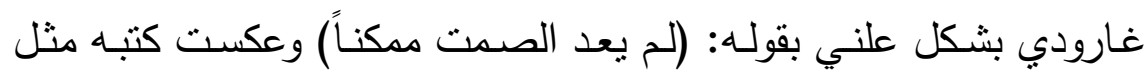

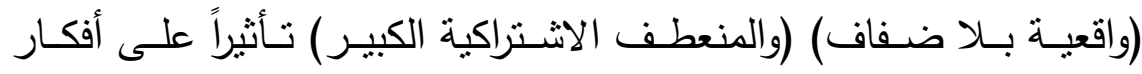

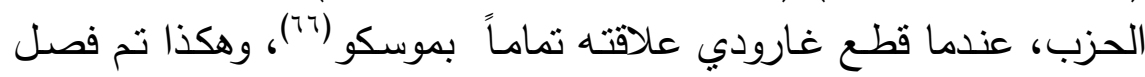

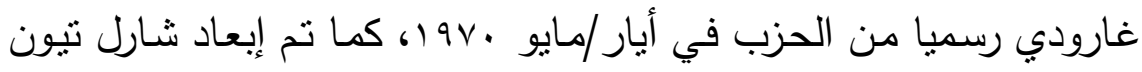

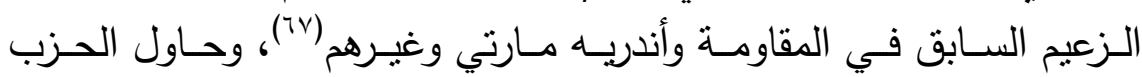
الثيوعي أن يثبت حضوره عندما قدم مرشحه الخاص (دوكلو) بعد استقالة ديغول 979 19، ومن جهة ثانية، دخل الحزب الثيوعي الفرنسي في حوارات مـع الحزب الاشتراكي بهدف الوصول للسلطة، فتم الاتفاق في vون حزيران

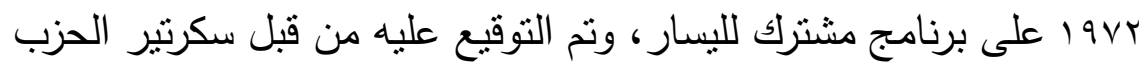

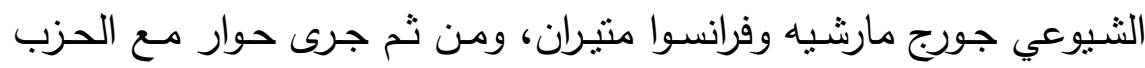




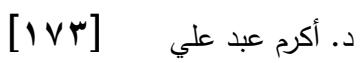

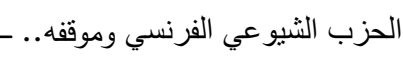

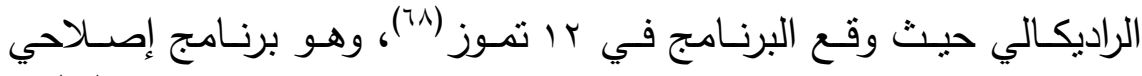

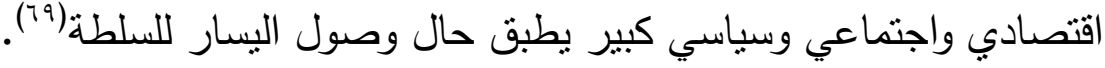

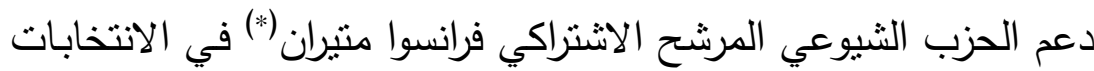

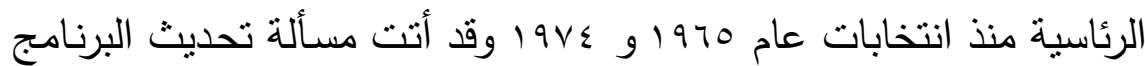

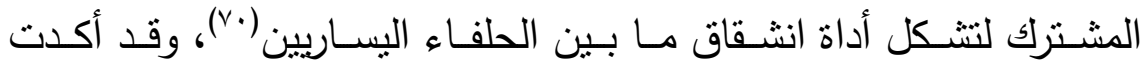

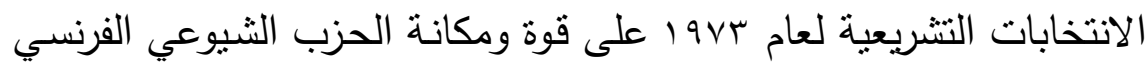

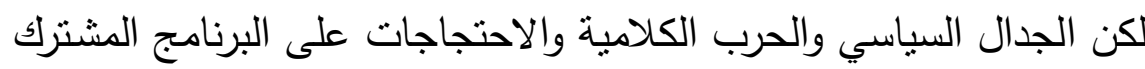

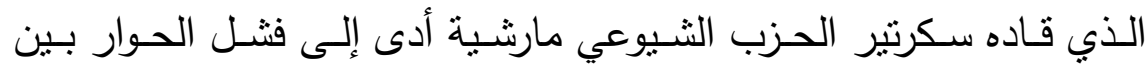
الطرفين، وانفصام التحالف مؤقتا ليعود لاحقا في الانتخابات التتريعية في

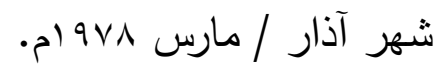

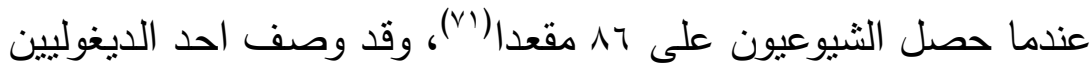

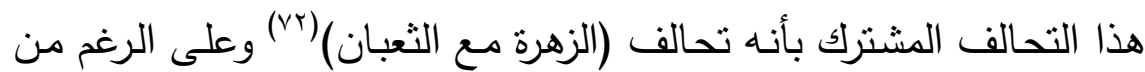

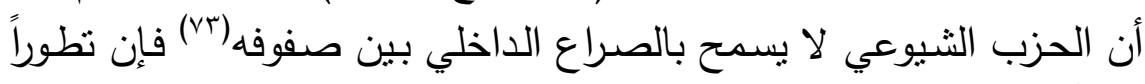

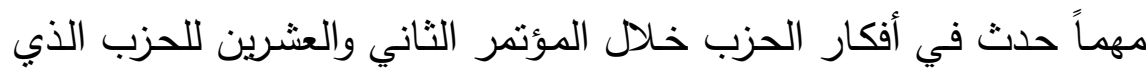

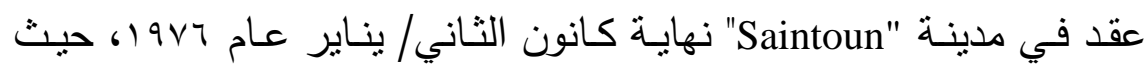

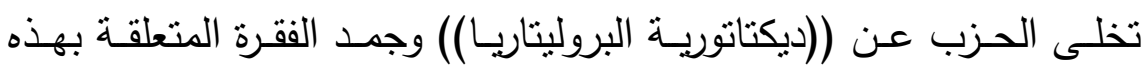

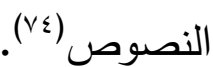

أمسا أبرز أسباب التخلي فهي اتهام الحزب الثيوعي بأنه حزب مستبد ضد الحرية وهو مجرد أداة للسوفييت وان كلمة (ديكتانورية) مقترنة بأذهان النيان

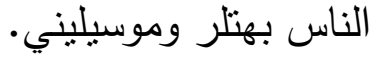
أمسا على صعيد الكسب والثنعبية داخلياً وخارجياً، فقد وجد الثيوعيون

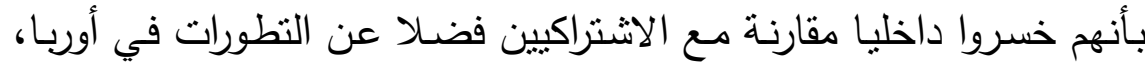

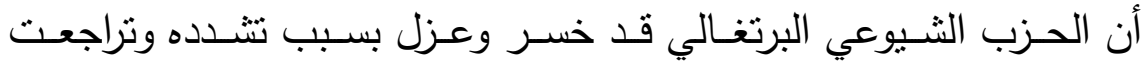
شعبيته، في حين حصد الحزب الثبوعي الايطالي نسبة كبيرة من الثعبية 
بسبب انفتاحهـ لذلك اقتتع الحزب الثيوعي الفرنسي بـان الوصول للسلطة

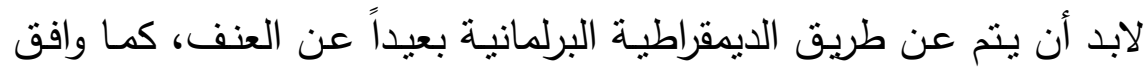

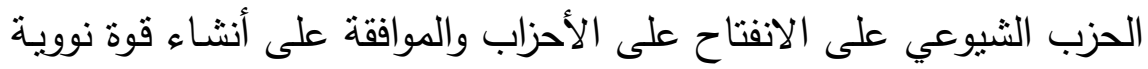

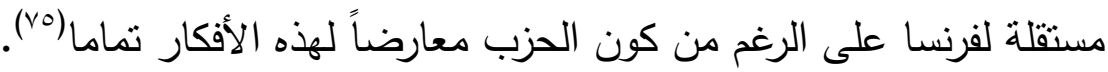

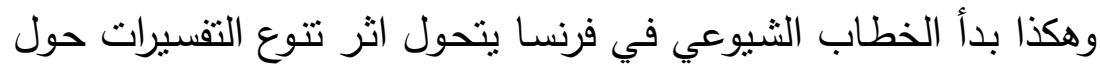

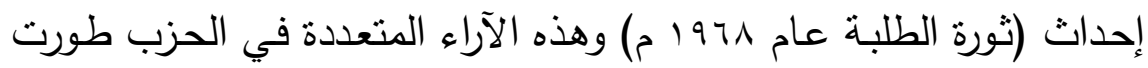

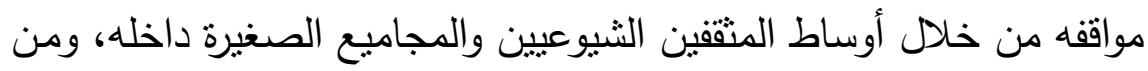

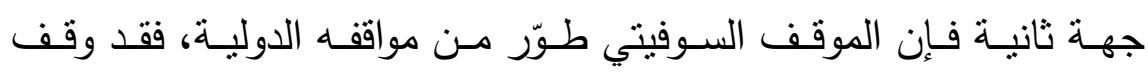

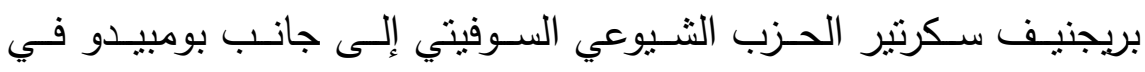

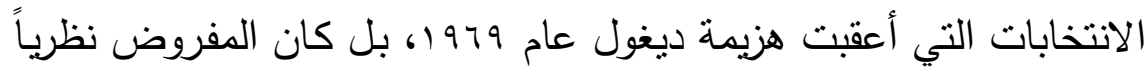

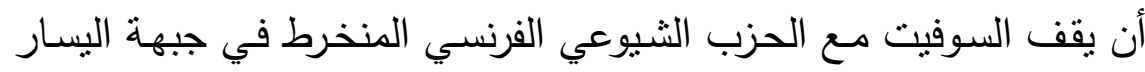

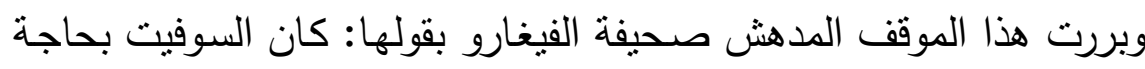

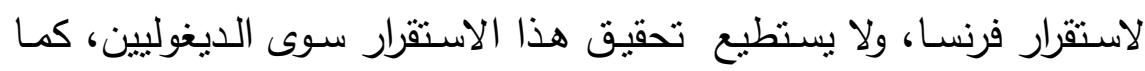

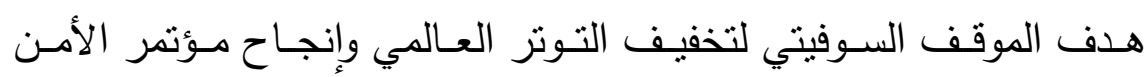

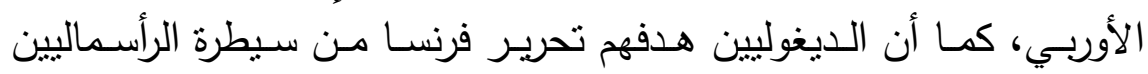

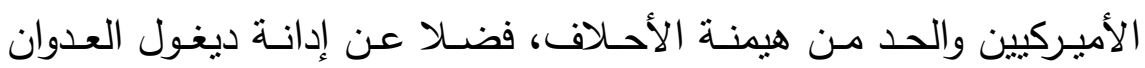
الأمريكي على فيتتام.

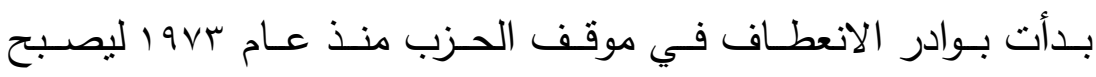

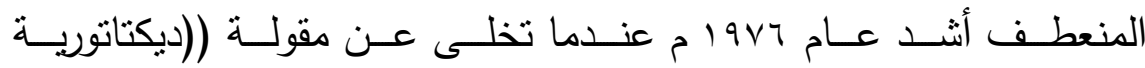

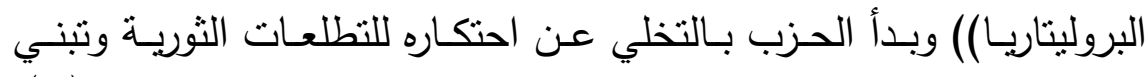

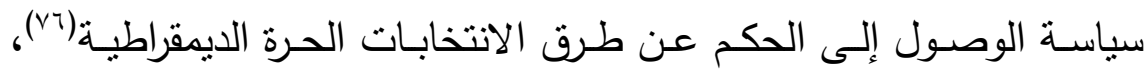

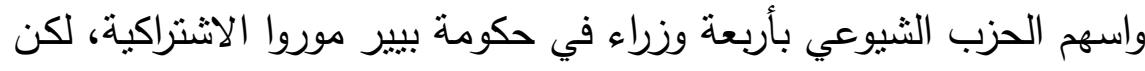

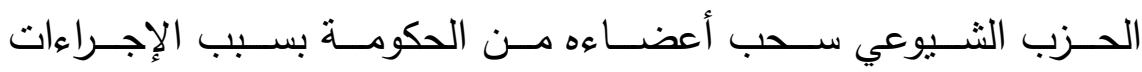

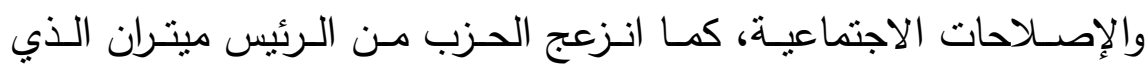




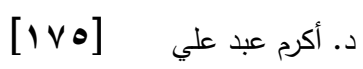

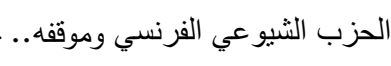

وصف سياسة الاتحاد السوفيتي بالتتدد، وأنتقد الحزب موافقة الرئيس ميتران

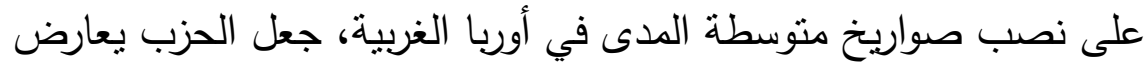

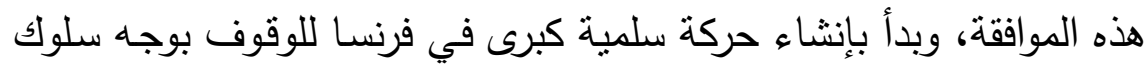

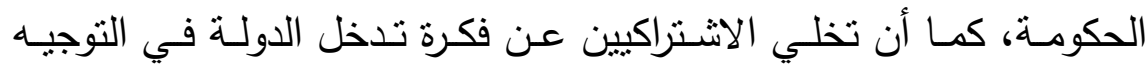

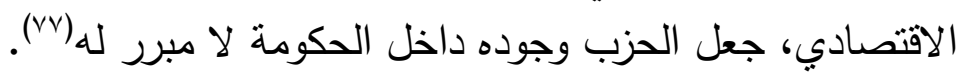

المحسور الثاني: موقف الحزب الثـيوعي الفرنسـي مـن بعض القضـايا العربية أولاً : المواقف العدائية أ- قضية الاسكندرونة، والجلاء عن الأراضي السورية لقد تذبذب موقف الحزب الثيوعي الفرنسي من القضايا العربية، ولاسيما

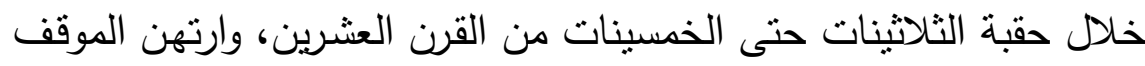

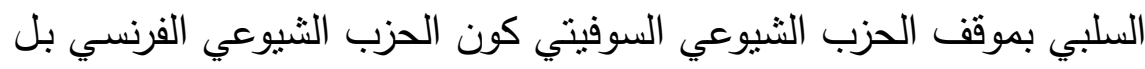

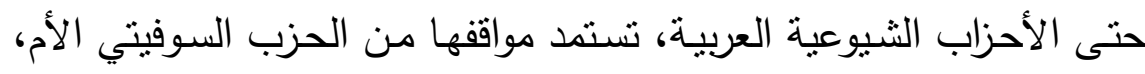

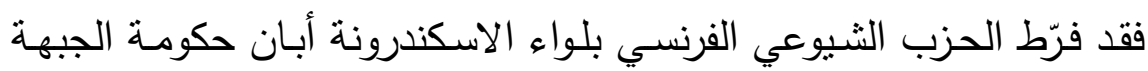

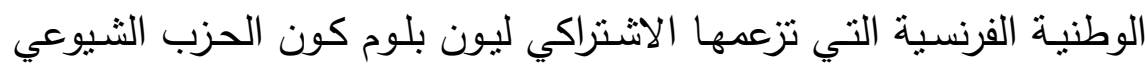

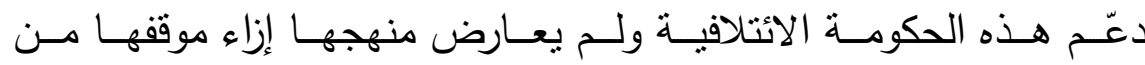

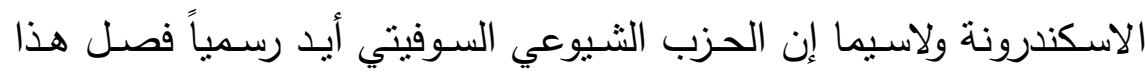

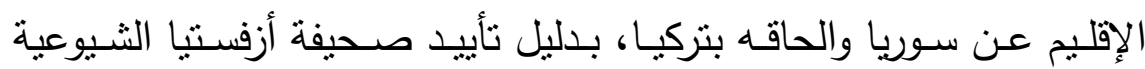

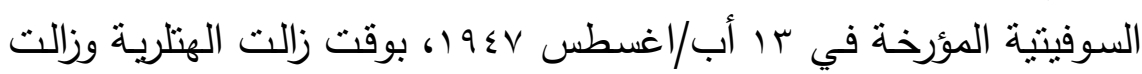

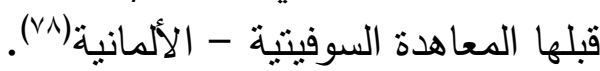

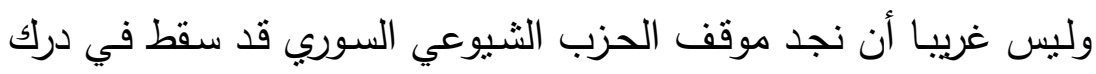
الخيانة الوطنية وصدت إزاء سلخ الإقليم تمشياً مع الموقف السابق العيق للحزبين 
الثـيوعي السـوفيتي والفرنسـي والذي يتعدى تـاريخ الاعتراف الرسـي في الصحيفة المذكورة(V9) (

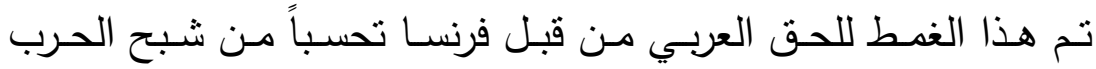

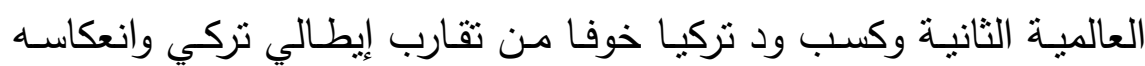

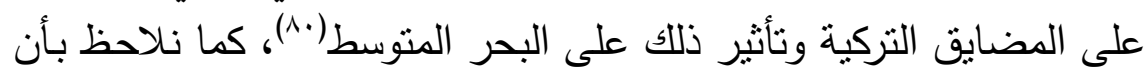

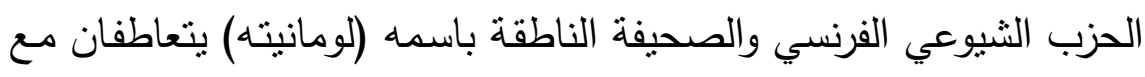

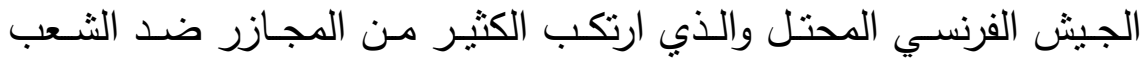

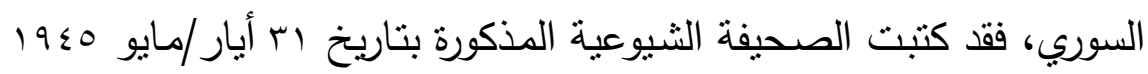
بقولهـا: ((أن الـدرك السـوري والسـكان قـاموا بمهاجمـة الحاميـة الفرنسـية)) وتتاست هذه الصحيفة بأن سوريا بلد مستقل، واعترفت فرنسا باستقلاله، وأن

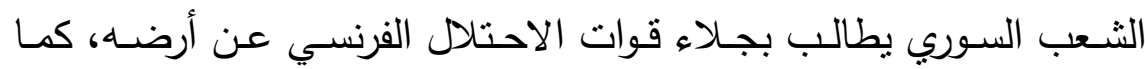
أصـدر الجنرال "أوليفـا روجيـه ب.Rogit" سكرتير منظمـة أنصـار السـلام

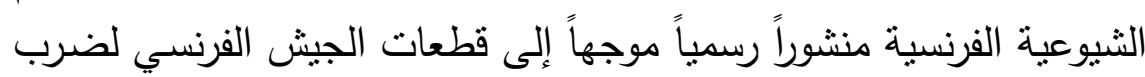
مراكز الثوار والقضاء عليهم، وهو من المشاركين في حكومة فرنسا إذ لعب إبه إنه

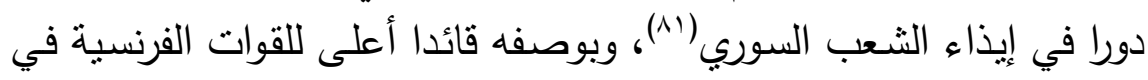

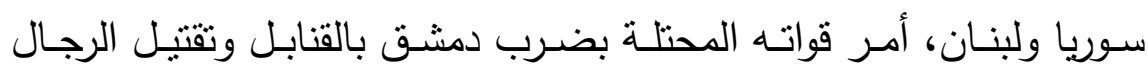

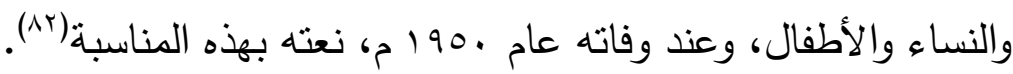

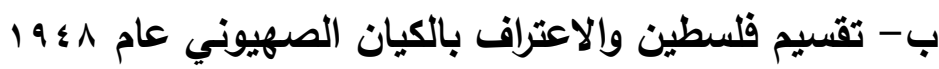

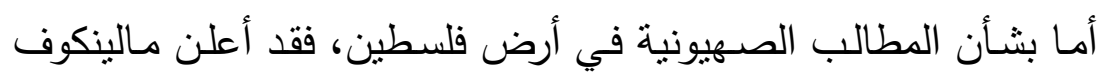

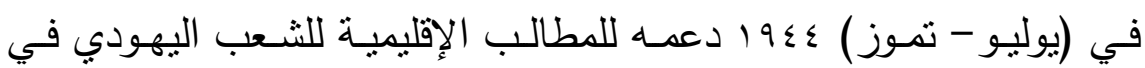

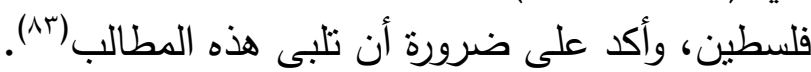

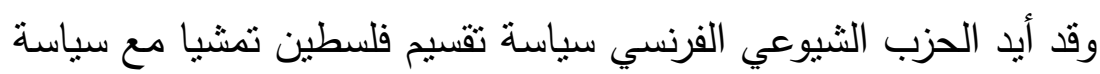
موسكو، حيث لعب مندوب الاتحاد السوفيتي في الأمم المتحدة خـلال الفترة

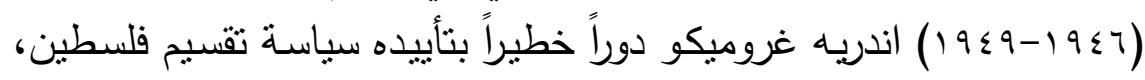


[ivV] [د أكرم عبد علي

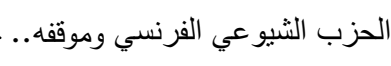

وانتقاده الثديد للجيوش العربية التي ساندت الفلسطينيين، عندما وصف هذه

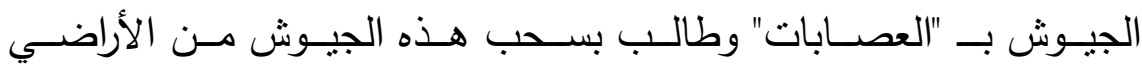

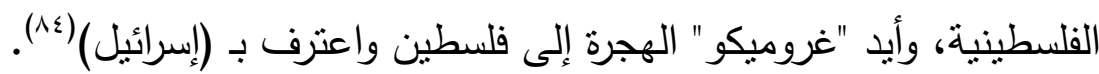

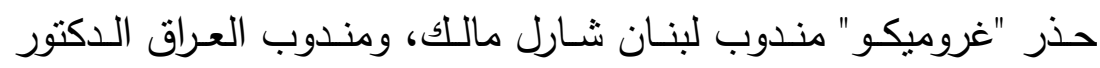

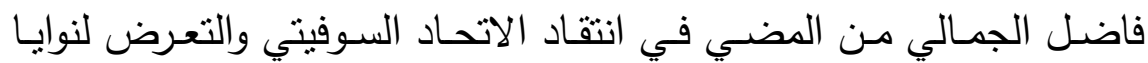

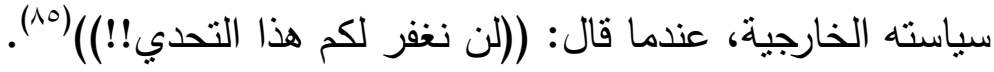

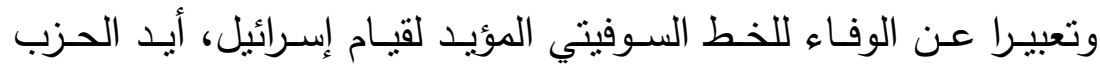

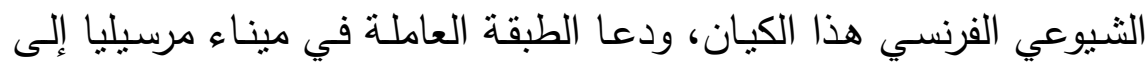

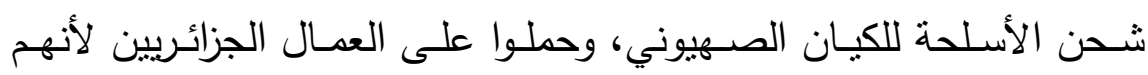

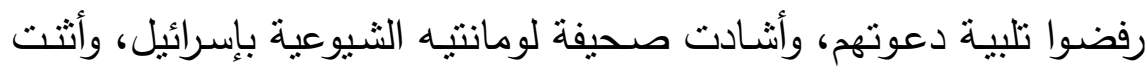

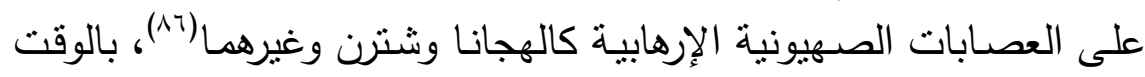

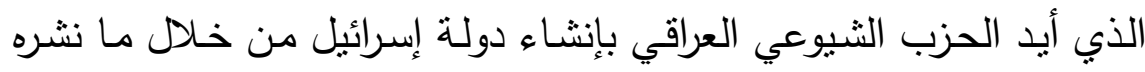

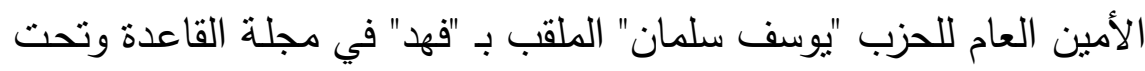

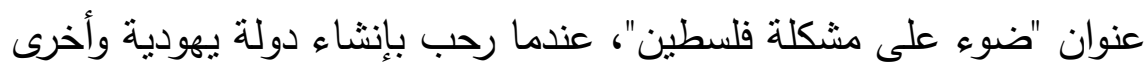

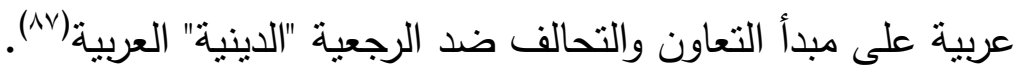
ج- الموقف من مصر مبر المبن

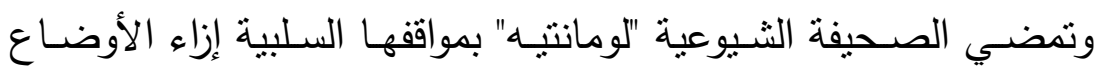

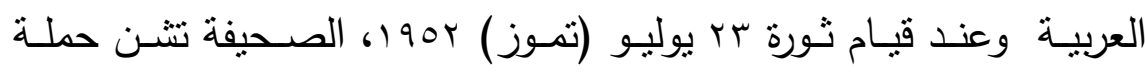

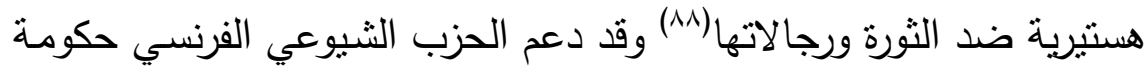

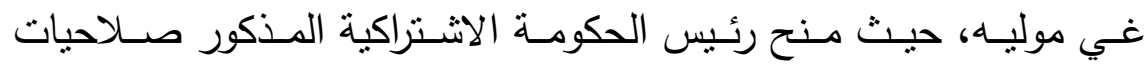

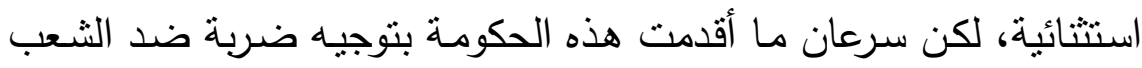

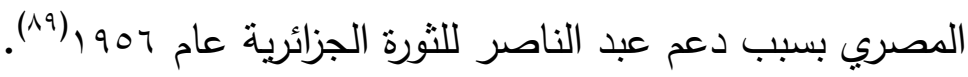

ثانيا- موقف الحزب الثيوعي من تأميم قناة السويس عام 1904 
تحت تأثنر الموقف السوفيتي الداعم لتأميم قناة السويس وسياسـة عبد

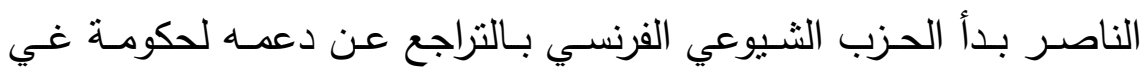

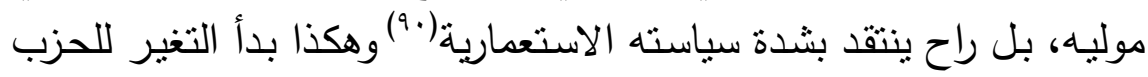

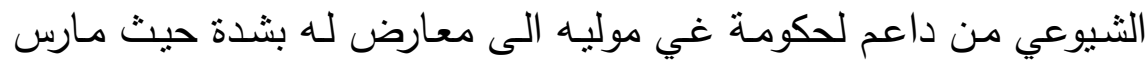
نوعا من الازدواجية خلال فترة قصيرة عام 1907 1، ويرجع ذلك دئ إلى الانسجام

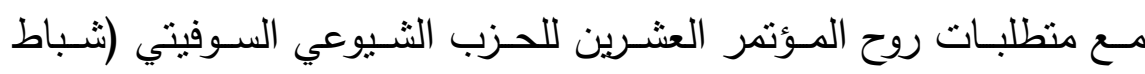
1907)، الذي دعا إلى التعاون بين الثيوعيين والاشتراكين (19).

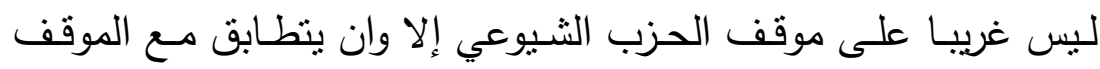

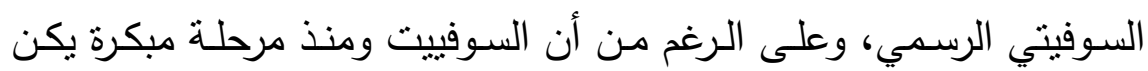
كراهية لعبد الناصر ولا تثت بسياسته، بل هاجمت الصحافة السوفيتية عبد الصن

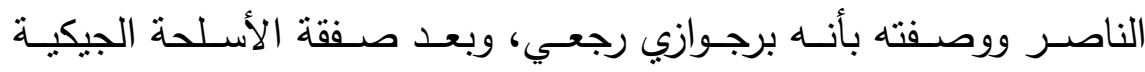

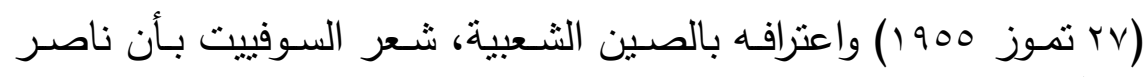

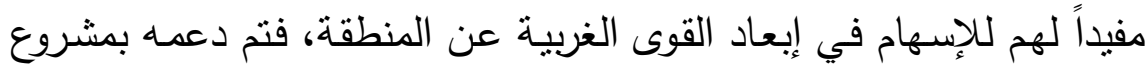

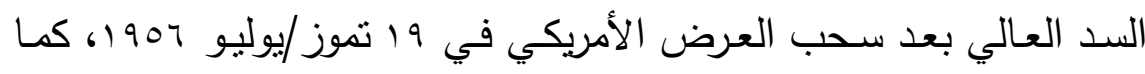

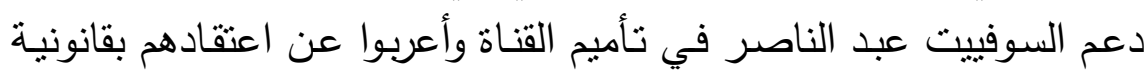
التأميم في المحافل الدولية، كما عارض السوفييت الإدارة الدولية لثركة قناة

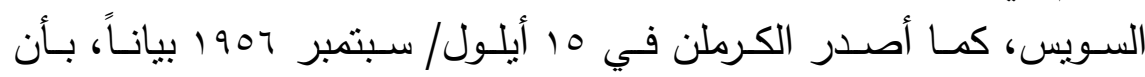

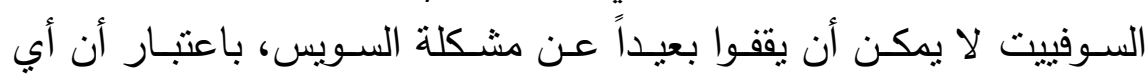

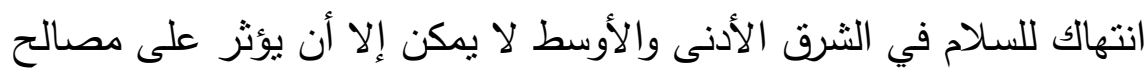

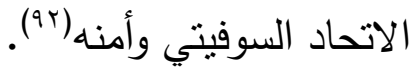

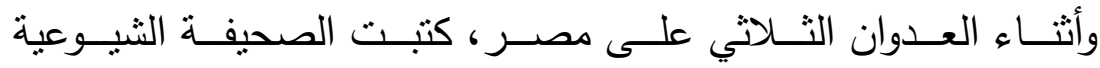
المرسييز "LA Marseillaise" مستتكرة التدخل الفرنسي في مصر ، وسخرت من ازدواجية حكومـة غي موليه، فهي تارة تتحدث عن السلم، وتارة ثانية

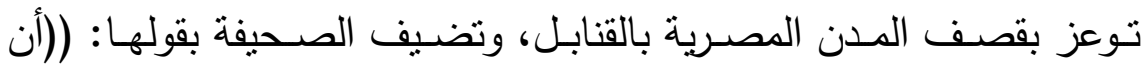




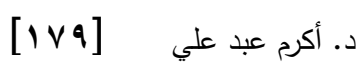

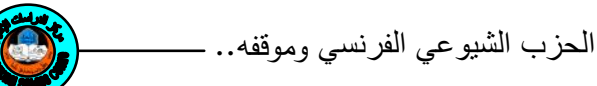

الديمقراطيات لا تسعى للحرب بل إلى احترام قرارات الأمم المتحدة))، كما

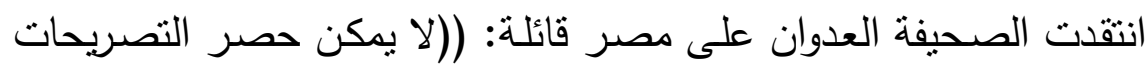

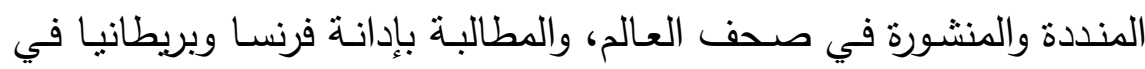

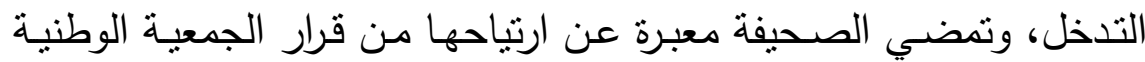

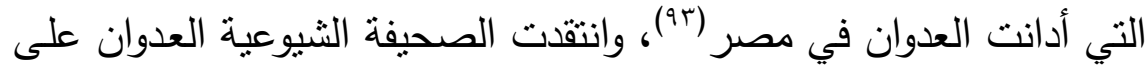

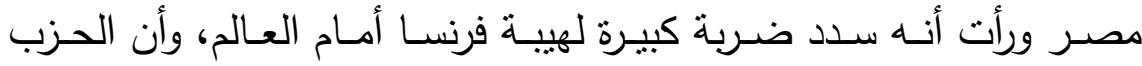

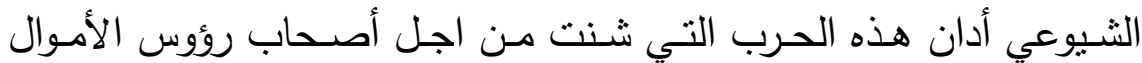

وتحت عنوان لإيجاد مخرج "Pour en Sortier" بقلم الكاتب الثيوعي الثـهير "مارسيل كارسو "Marcel Carasso" حيث كثفت الصحيفة عن لت

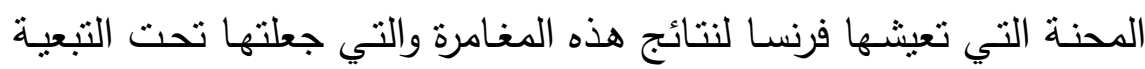
للولايات المتحدة وأصبحت أسيرة سياسة الأمريكان (90).

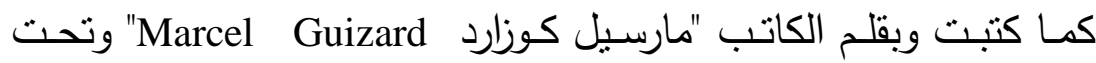

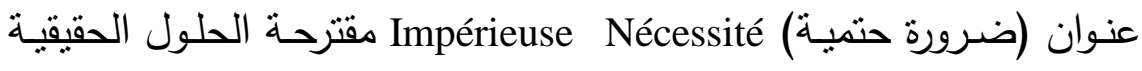

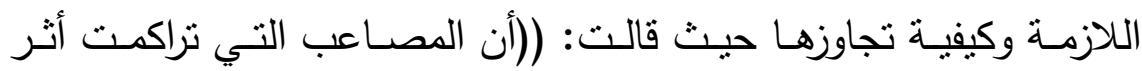

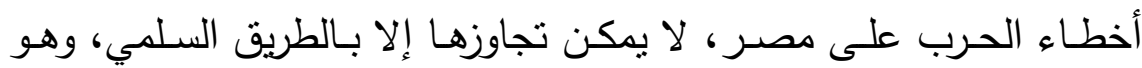

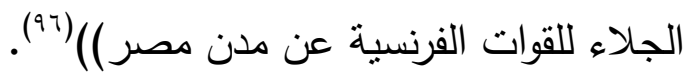

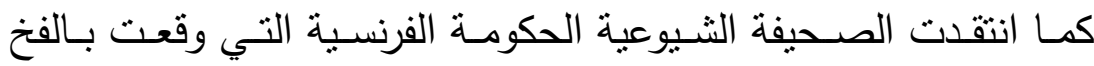

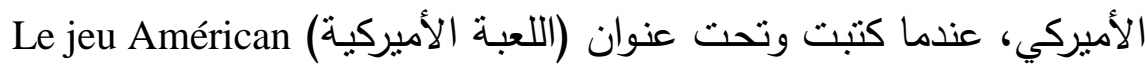

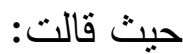
(إن الولايـات المتحدة لا نرغب سوى إزاحسة الأمم العجائز ، وقد بـلتل

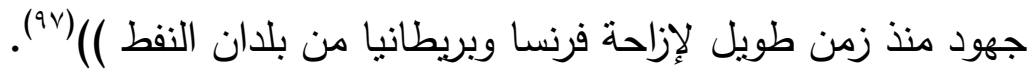
ثالثا: موقف الحزب الثيوعي الفرنسي من عدوان الخامس من حزيران 


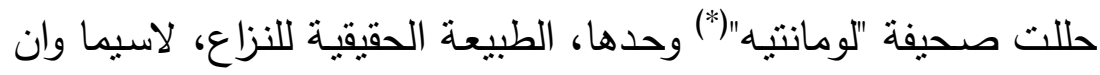

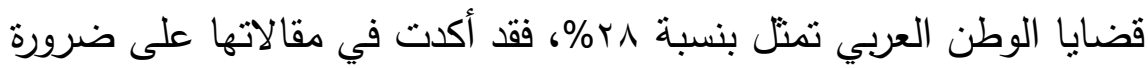

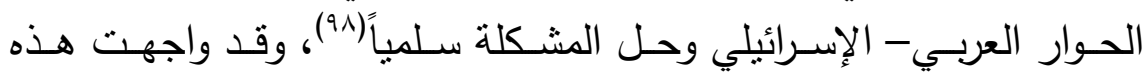

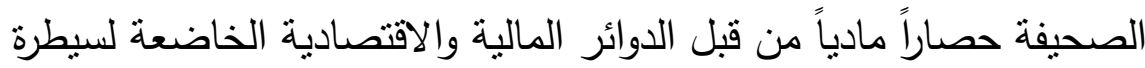

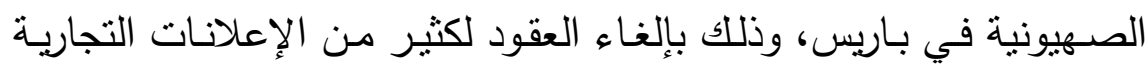

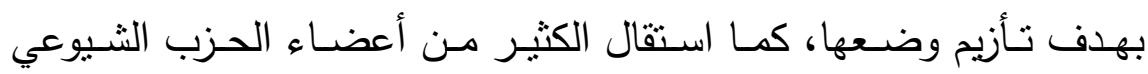

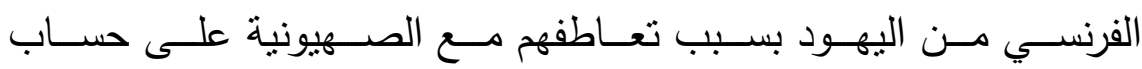
ايديولوجيتهم (99).

وقد هاجمت صحيفة لومانتيـهـ الكيـان الصـهيوني بكل عنف فكتبت:

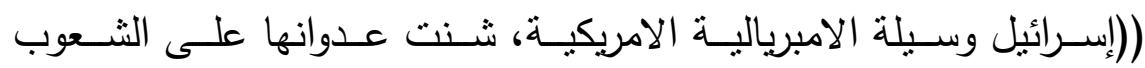

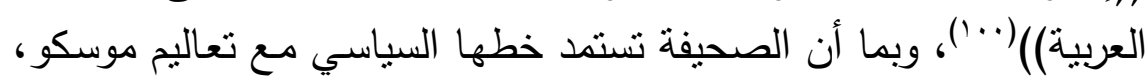

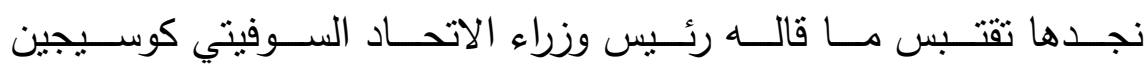

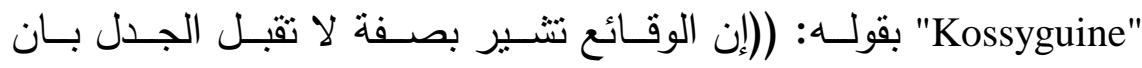

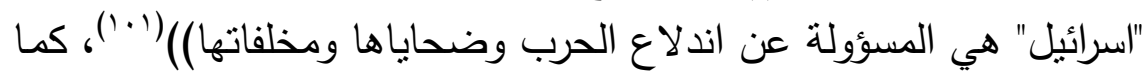

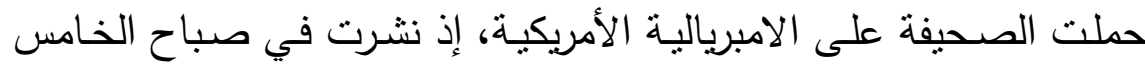

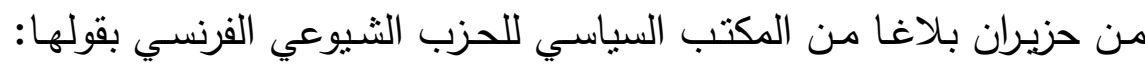

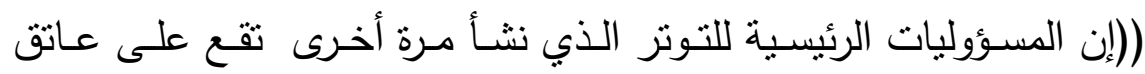

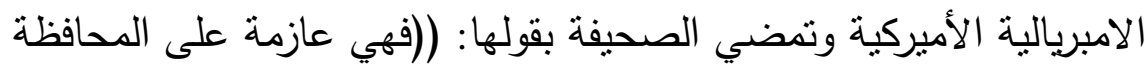

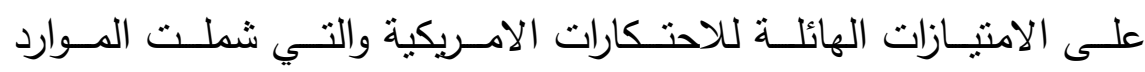

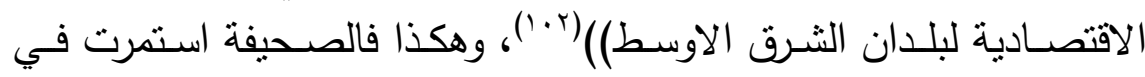

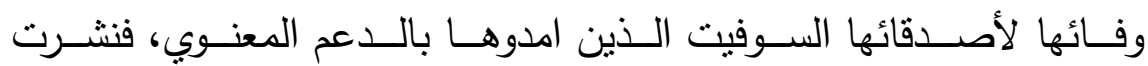

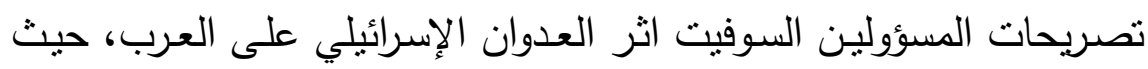

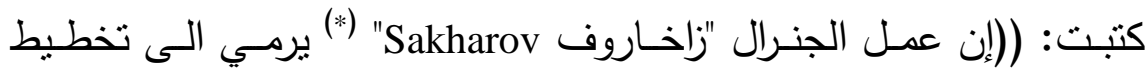

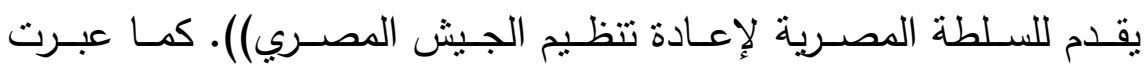




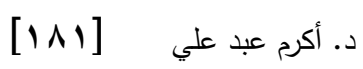

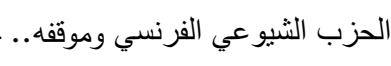

الصحيفة عن انسجامها مع موقف الاتحاد السوفيتي بصدد الصراع بالثرق

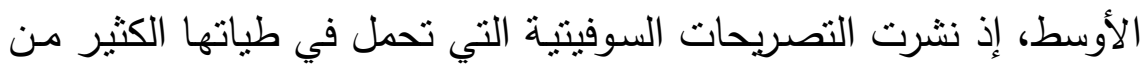

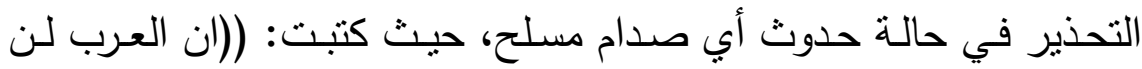

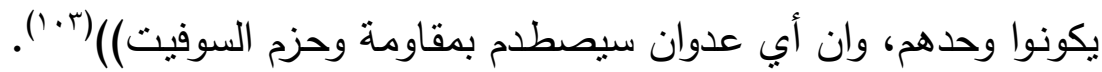

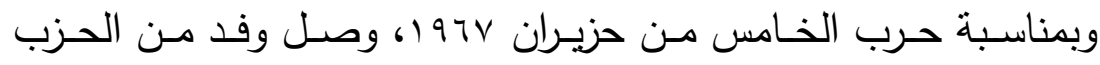

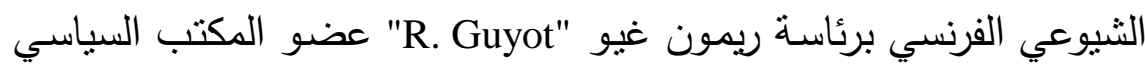

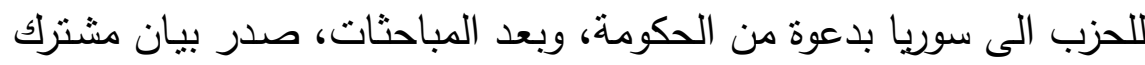

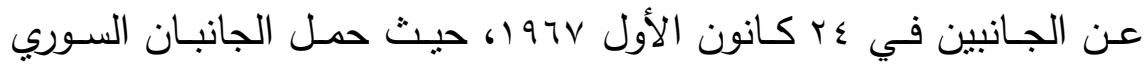

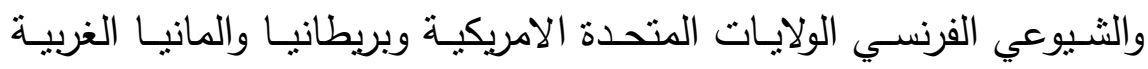

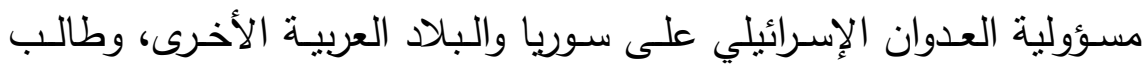
الفريقـان انسـاب القوات الإسـرائيلية من الأراضـي العربيـة المحتلة وعودة الإلية اللاجئين الفلسطينيين الى ديارهم (ع.1).

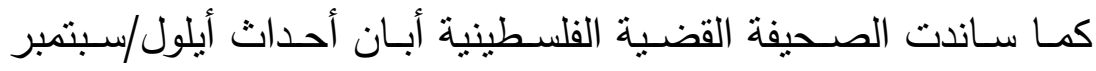

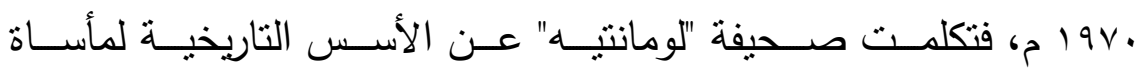

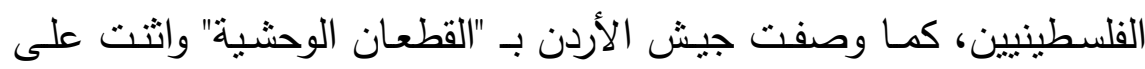

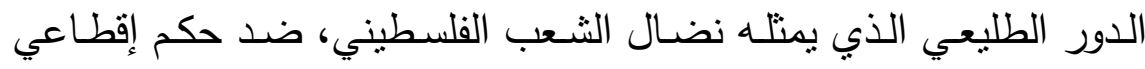

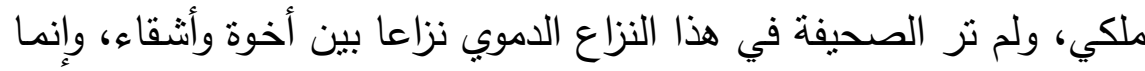

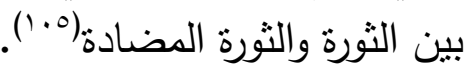

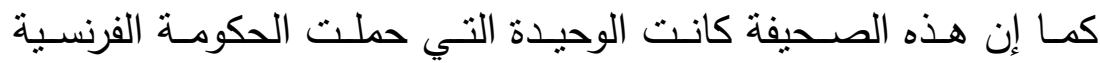

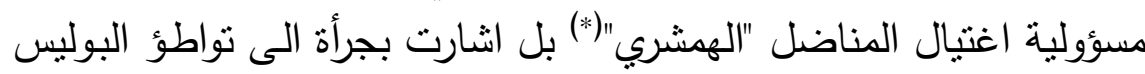

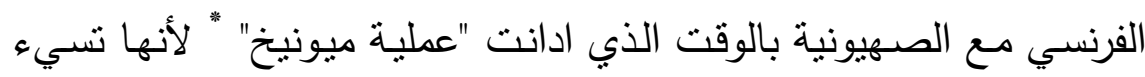
الى القضية الفلسطينية. كما افرد "جاك كوبار" محرر صحيفة "لومانتيه" والمختص بشؤون الثرق التوق

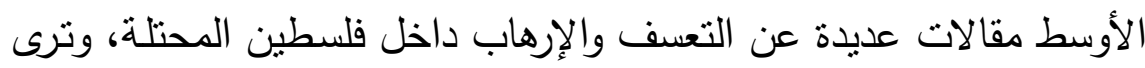


الصحيفة الثيوعية بان الحل السلمي في الثرق الأوسط هو المنبثق عن

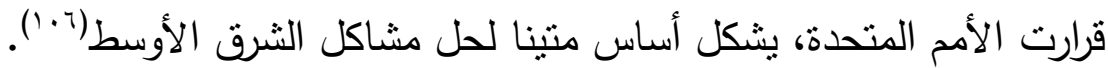

رابعا: موقف الحزب الثيوعي من حرب تثرين الاول / اكتوير مVY

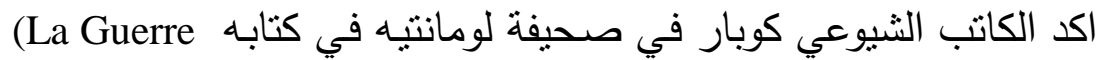
des 6 Jours)

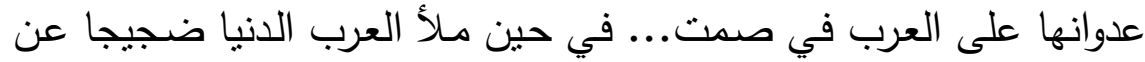
خططهم وأعمالهم... وفي عام 19 إ فعل السادات العكس إذ اعد مخططه

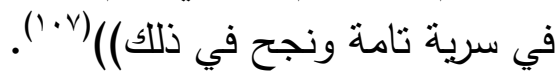

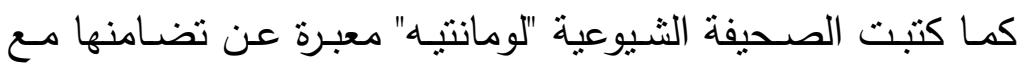

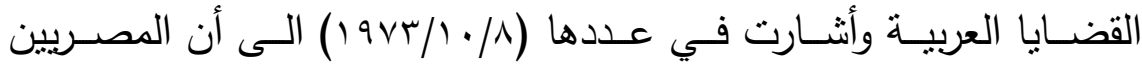

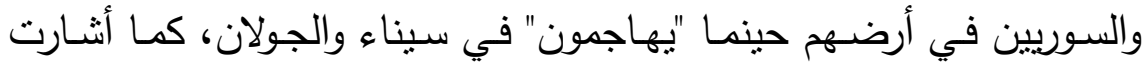

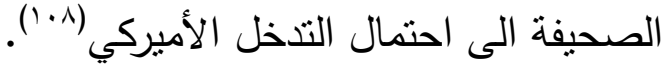
وكان موقف الحزب الثيوعي الفرنسي واضحا من القضايا العربية، وفي

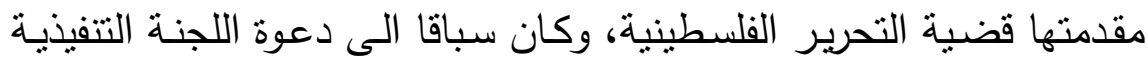

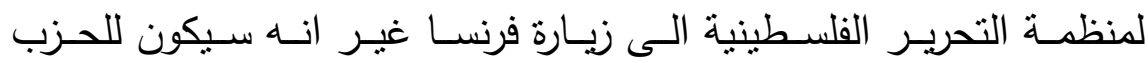

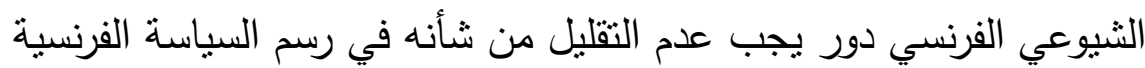

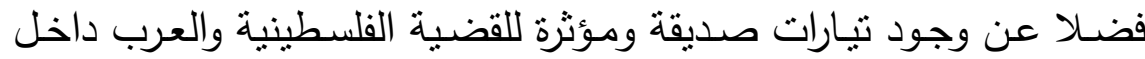

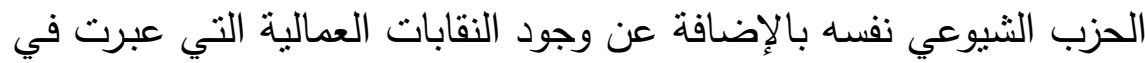

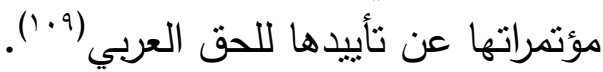

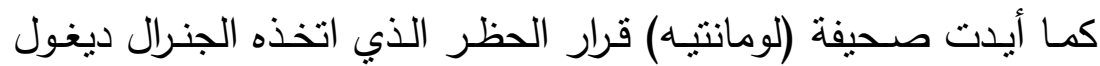
حول تصدير الأسلحة الى اسرائيل، ووقف تزويد إسرائيل بالطائرات المقاتلة ( الميراج ) التي كان لها اكبر الأثر في فعالية الهجوم الإسرائيلي خـلد الإل الحرب('). 


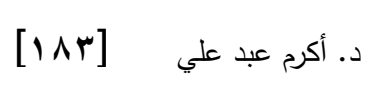

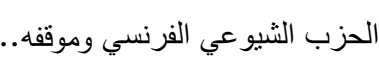

إن معظـم الصـحف الفرنسـية اعتمـدت في أخبارهـا علـى المصــادر الصهيونية، باستثناء صحيفة لومانتيه، فإنها اعتمدت على المصادر العربية والإسرائيلية معا خلال حرب "أكتوبر"، وعبرت الصحيفة المذكورة عن موقف باءه إعلامي مؤيد للعرب وللمقاومة الفلسطينية ومناهض لإسرائيل(' (')"، كما أكد

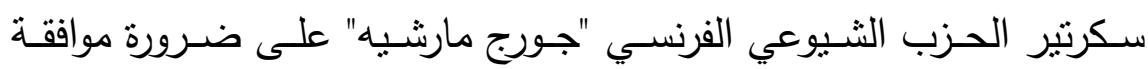

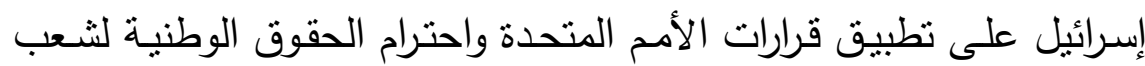
فلسطين، وأكد أيضـاً بـان تبني "اسـرائيل" لمثنل هذه السياسـة سيؤدي الى الى الى

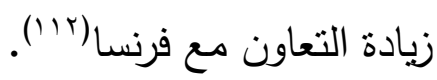




\section{الاستتتاجات}

ا. ظهر الحزب الثيوعي الفرنسي نتيجة للمواقف المتباينـة في التجمعات الاشتراكية خلال مؤتمر "تور" من الثورة البلثفية.

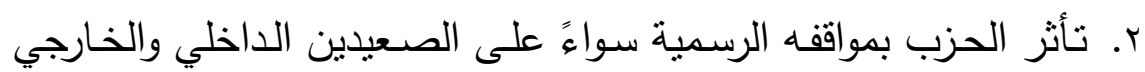
بما تمليه عليه مواقف الحزب الثيوعي السوفيتي.

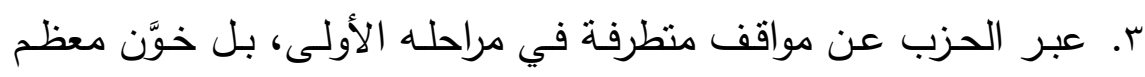
الأحزاب وآمن بالعنف للوصـول الى السلطة في وقت غابت فيسه روح

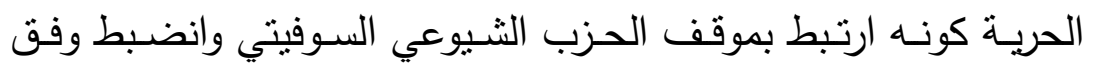

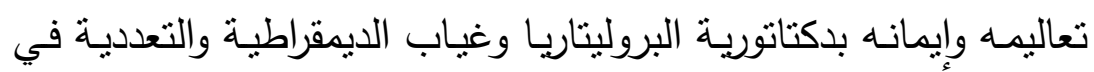
أفكاره. ء. بسبب مركزيـة الحزب وغياب سـاحة الحربـة، انثقت عنه الكثير مـن القيادات المتقفة وأصبحت في الخندق المناوىء لأفكاره الجامدة.

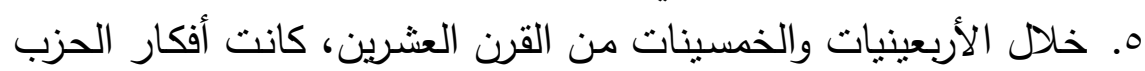

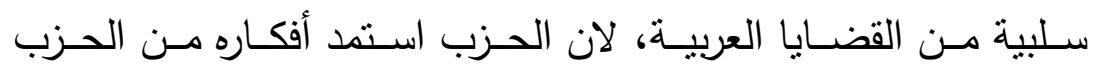

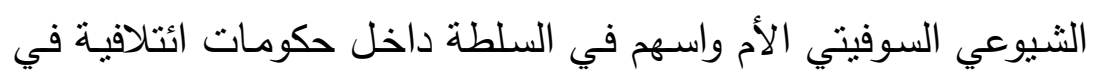

؟. تعرض الحزب الى الكثير من الضربات السياسية والضغوط في مسيرته

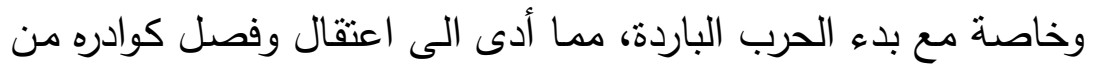
قبل الحكومات الفرنسية.

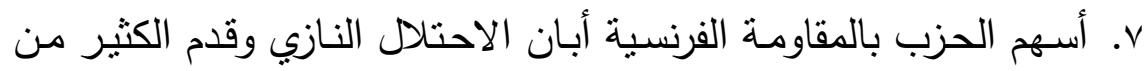

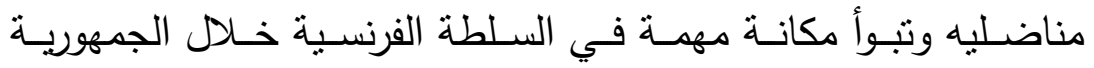
الفرنسية الرابعة. 


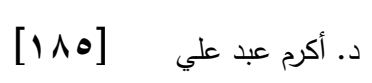
الحزب الثيو عي الفرنسي وموقفه.. - م

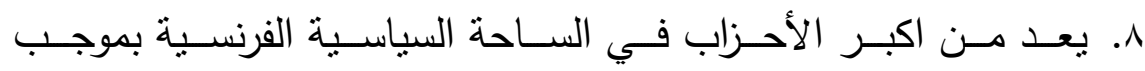

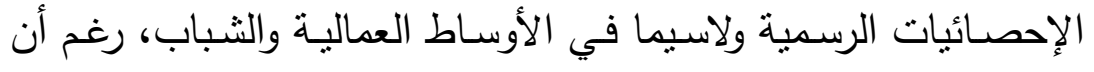
دوره بدأ بالافول لصالح الحزب الاشتراكي الذي يستجيب لواقع فرنسا.

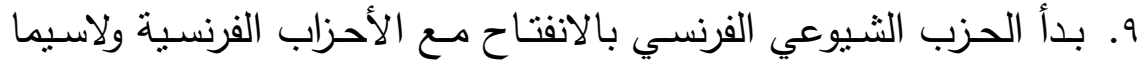
أحزاب اليسار في برامج مشتركه وبدا التخلي عن دكتاتورية البروليتاريا اثر حوادث ثورة الطلبة والتدخل السوفيتي في جيكوسلوفاكيا (السابقة)، .1971

• 1. اخفق الحزب الثيوعي في الوصول للسلطة، رغم كثافة شعبيته، لان الأحزاب الفرنسية تخثى مـن تطرفه، فتتوحد وتتكتل لتعيـق وصـوله

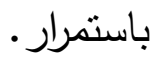


دراسات إقليمية 7 (19)

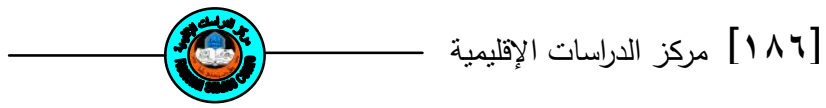

\title{
The French Communist Party and Its Attitude From The Contemporary Arab Issues
}

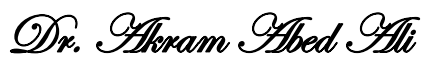

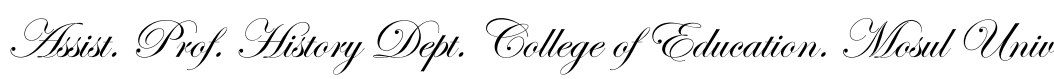

\begin{abstract}
The Paper handles the French Communist Party due to its importance on the political, internal and foreign arena and its attitude from contemporary Arab issues, We talk about the reasons of its unstable attitudes from these issues and the Violence as a means to reach authority as the prolitaria dictatorship which doesn't believe with the plurality.

Then the party neglected the thoughts and its belief in democracy to reach power and to share the other local parties. The party played an important role in resisting the Nazi Germany which occupied France during the world War II (1940-1944).

The Party took in the power during the fourth been dismissed from Ramader Government during the Gold War and the party has given exaptional authorities to guy mollet, the head of the French government in 1956 and it withdrew from it when the Triaggression on Egypt 1956.
\end{abstract}




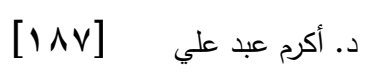

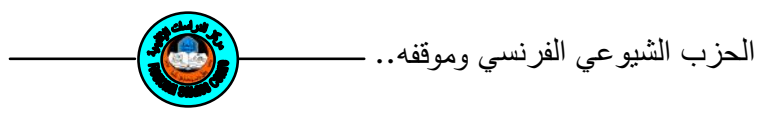

(1) موريس دوفرجيه، المؤسسات السياسية والقانون الدستوري، ترجمة جورج سعد، المؤسسة الجامعيـة

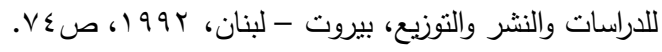

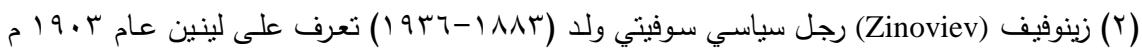

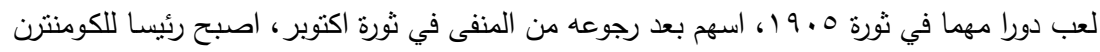

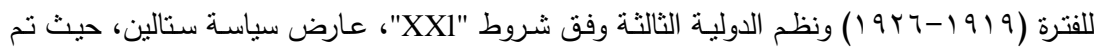

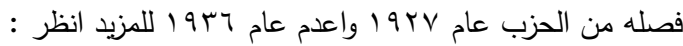

Dictionnaire encyclopédique pour touş petit Larousse, Libraire, Paris Vie, 1981, P.

1791

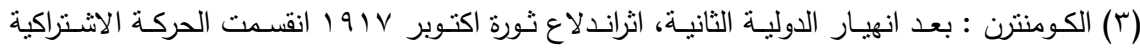

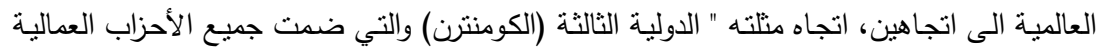

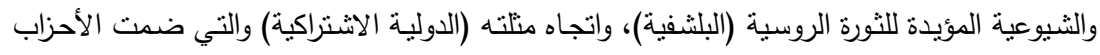

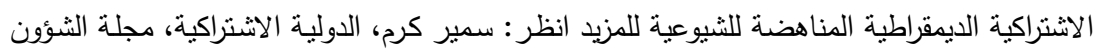

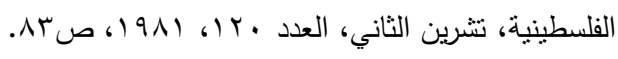

(*) (S.F.I.C (Section Fransaise de l'international communiste).

(*) (P.C.F.) : Parti Communiste français).

(*)S.F.I.O (Section Francaise de l'international ouvriere).

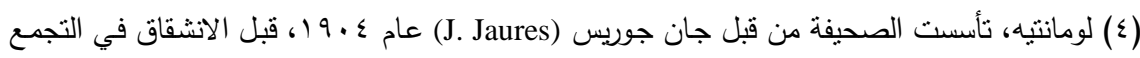

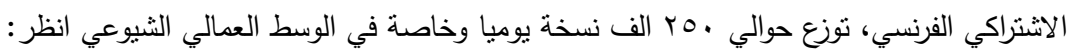

Akram , A,Ali , La Crise de suez Vue Par La Presse regionale Française , These de Doctrot, France 1988, P.23

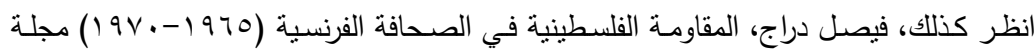

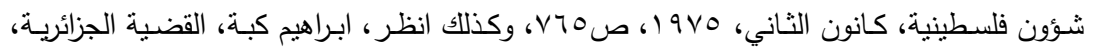

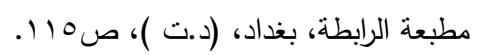

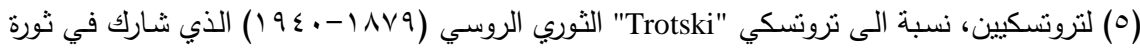

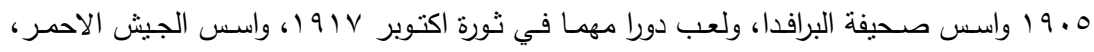

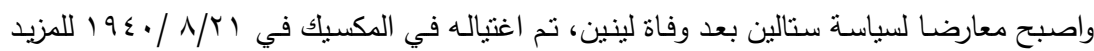

Michel Mourre, Dictionnaire d'historie universelle, Bordes , I.S.B.N Paris , 1981 , P. 1714. 
وكذلك، نعمان احمد الخطيب، الأحزاب السياسية ودورها في نظرة الحكم المعاصرة، جامعة مؤتة،

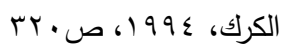

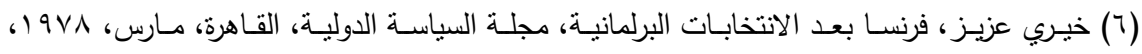

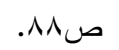

( $\vee$ )André, Akoun, Dictionnaire de politi que, Larousse, Paris v1, 1979 , P.59

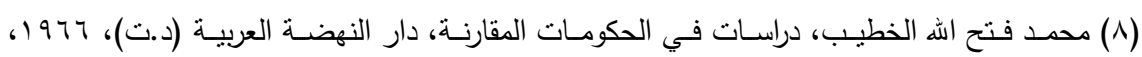

(9) خيري عزيز ، قاموس الأحزاب الثيوعية الأوربية، مجلة السياسة الدولية، مبا، العدد ـ، اكتوبر،

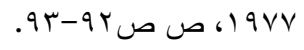

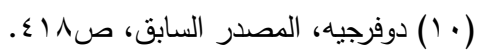

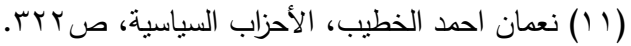

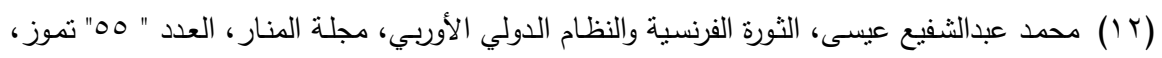

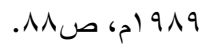

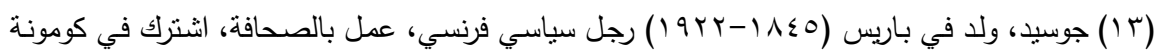

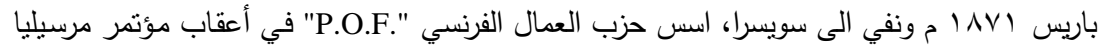

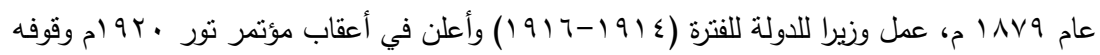

M. Mourre, Op. Cit , P.701

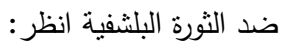

( 1 \&) P.O.F. (Patrti Ouvrier Fransais) M. Mourre, Op.Cit, P.1448.

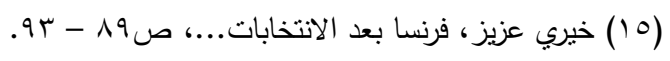

( 17 ) C. G.T.U. (La confederation generale du travial unitaire, M. Mourre, Op. Cit , P. 347.

( V v) C.G.T. (La confederation generale du travail M. Mourre, Op. Cit , P. 347.

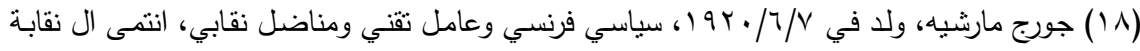

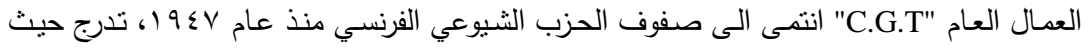

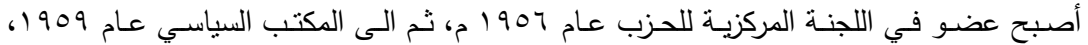

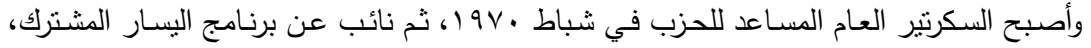

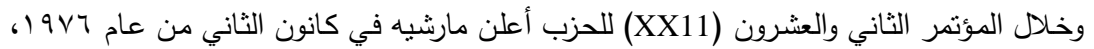

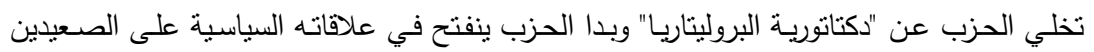
A. Akoun, Op.Cit , P.60.

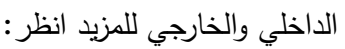




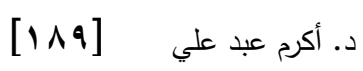

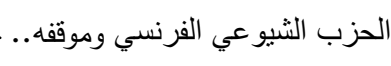

(9 (1) فيصل دراج، الحزب الثيوعي الفرنسي ودكناتوريـة البروليتاريـا، مجلـة الثقافة، العدد الاول، السنـة

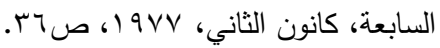

(ץ.) A.Akoun, Op. Cit , P. 60.

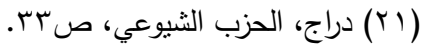

"Doriot" (YY)

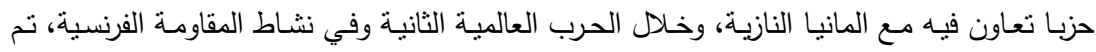

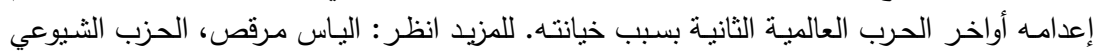

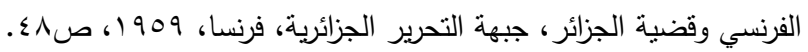

(rr) M.Mourre, Op. Cit, P.337.

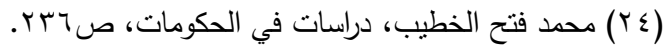

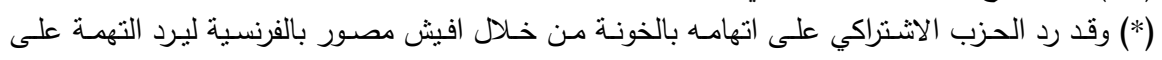

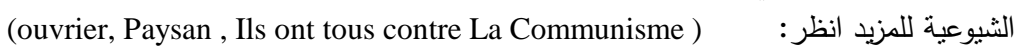

B.D. Roche, Le monde du xxe siecle, magnard , 1980 , P. 86.

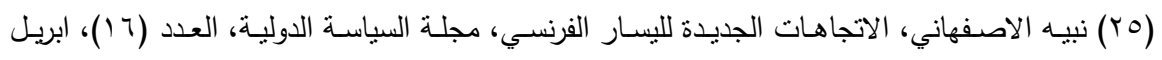

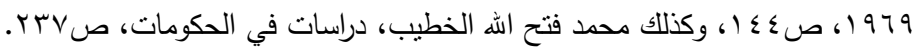

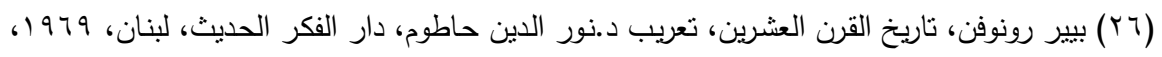

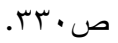

( $r V)$ A,Akoun, Op.Cit, P. 60.

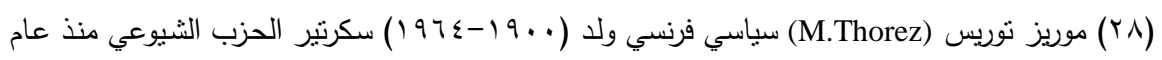

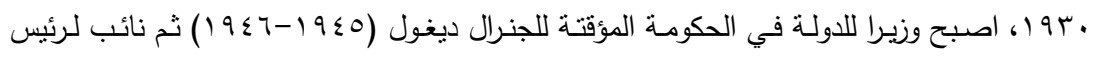

D. Encyclopédique , Op. Cit , P. 1729

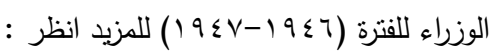

(") عصابات صليب النار : تنظيم يميني ظهر عام 19 إمي في فرنسا، بعد تحول جمعية قدامى المحاربين

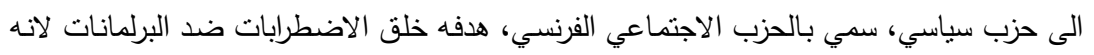

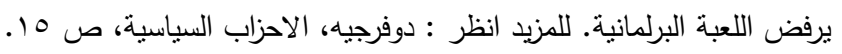

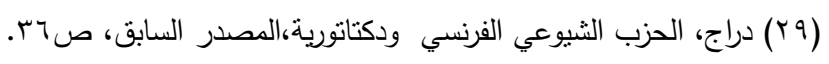

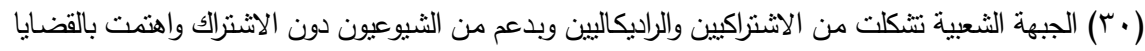

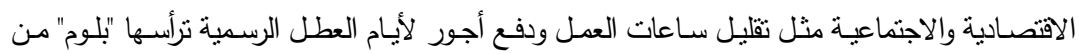

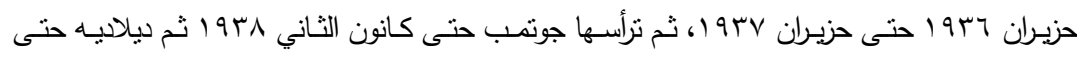

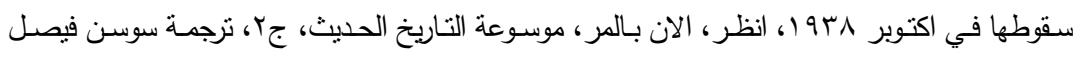

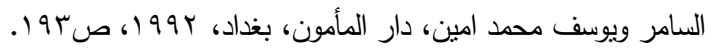

(५.) M.Mourre , Op.Cit , P. 335. 


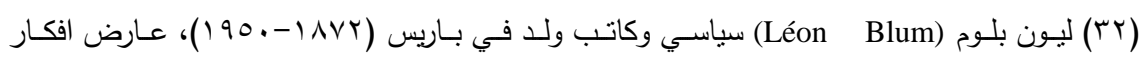

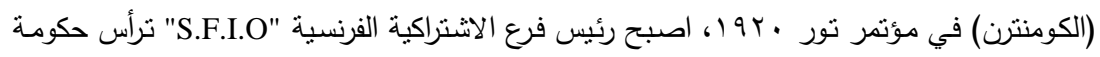

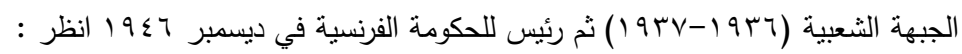

Encyclopédique, Lerouss, Op.Cit , P.1173

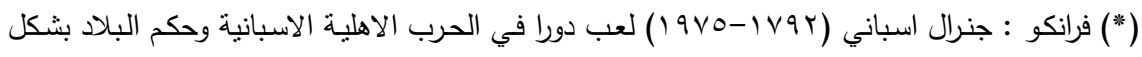

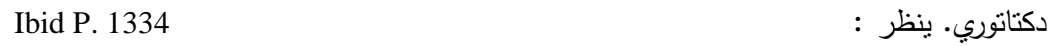

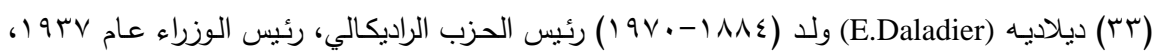

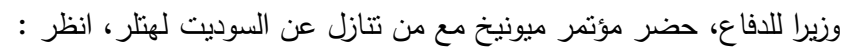

Ibid, P. , 1266

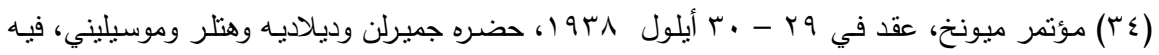

$$
\text { انحنى هؤلاء لمطاليب هنلر بصدئ عيد في السوديث انظر : }
$$

P. Miquel , Histoire dela france, marabout , 1976 , P.207

(1) أ.ج. كرانت وهارولد تمبرلي، تاريخ اوربـا القرن التاسع عشر والعشرين، ترجمـة محمد علي ابو درة

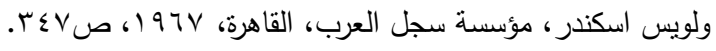

(५ч) B.D. Roche, Op. Cit. P. 91.

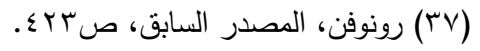

(r^) M.Mourre , Op. Cit , P. 336.

(५ १) C.N.R. (Le Conseil National de la Résistance, B.D. Roch, Op.cit, P.205.

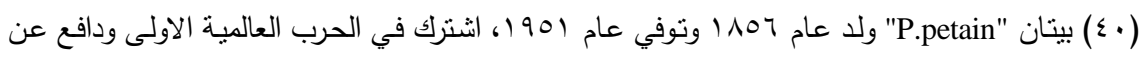

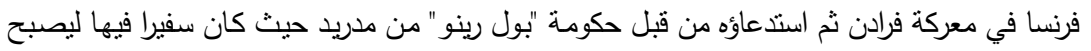

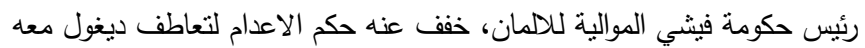

Mourre, Op.Cit ,p1198.

(1) موريس كروزيه، العهد المعاصر ، نقله الى العربية، يوسف اسعد داغر، فريد، م. داغر، منشورات،

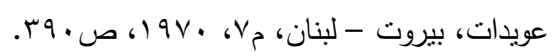

( $₹$ Y ) C.F.L.N. (Le comité Française de libération nationale). B.D. Roche , Op. Cit, P. 205.

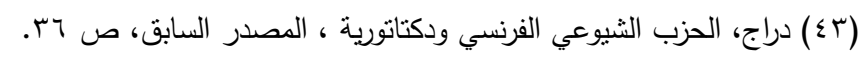

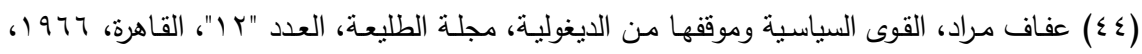

(£०) A.Akoun, op. cit , p. 59

(§૫) M.Mourre, op. cit, p. 337.

(§v) محمد فتح الله الخطيب، دراسات في الحكومات المقارنة، المصدر السابق، ص هبr. 


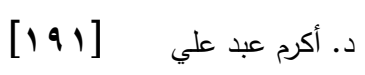

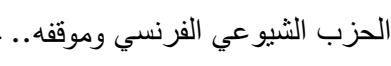

(§^) “MRP” Le mouvement Répubicain Poupulaire, M. Mourre, op. Cit, P.603 .

(§१) P. Miquel, Op. Cit, p. 210.

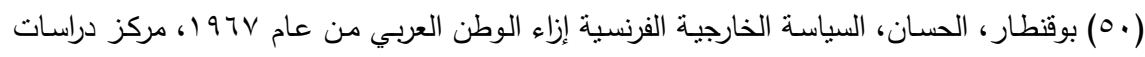

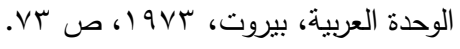

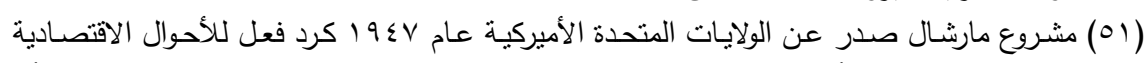

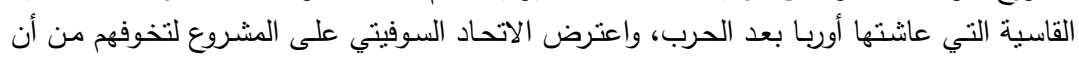

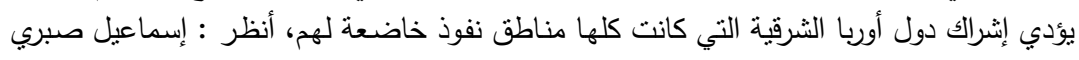

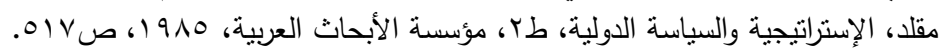

(Or) B.D.Roche, op. cit , p. 205

(r) Réné, sommer, La Quatrime Republique contre le P.C., L'histoire, N` 40, 1981, P. $26-29$.

(๑乞) M.E. Nacgelen, Ilya 10 ans (Budapest se Révoltait 1956, Historia No. 239, Octobre 1966, P. $73-83$.

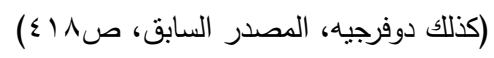

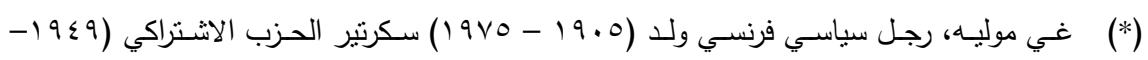

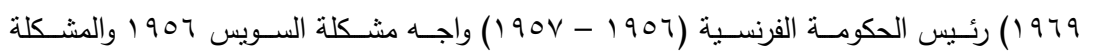

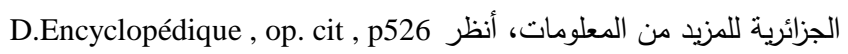

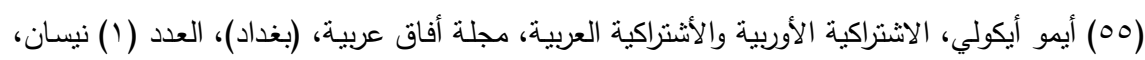

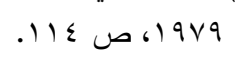

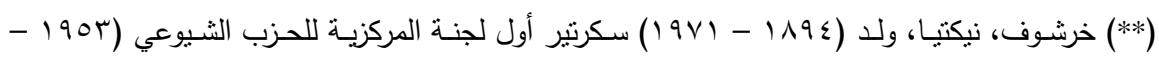

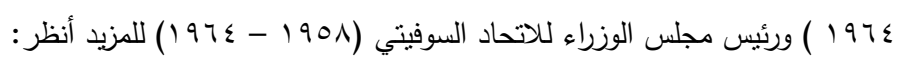

D. Encyclopédique, Op. Cit , p1441.

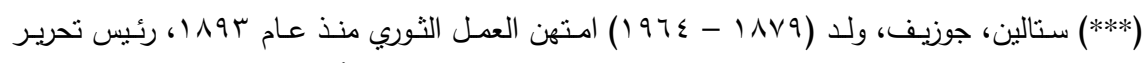

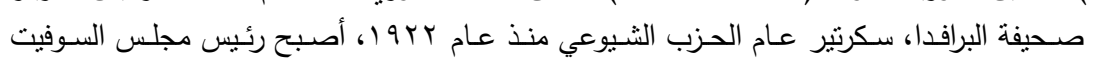

Ibid, p. الأعلى 1704

(07) M.Mourre,op. cit,p.337

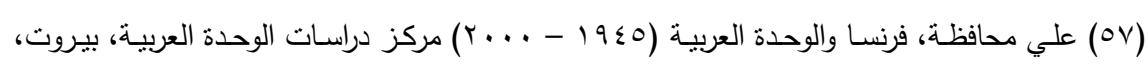

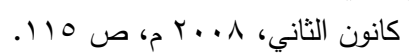

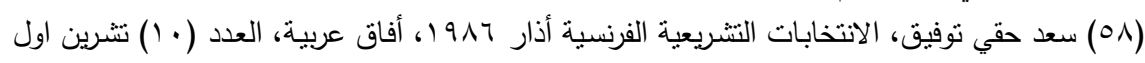
(9AV

(9 ( د داؤد نلحمي، القوى السياسية الفرنسية والمسألة الفلسطينية، مجلة شؤون فلسطينية، (بيروت)، العدد

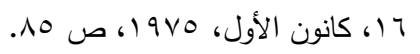




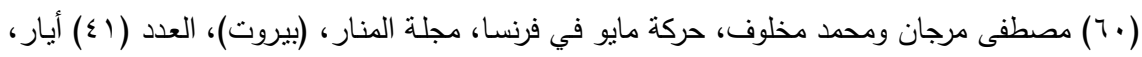

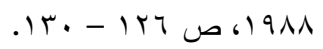

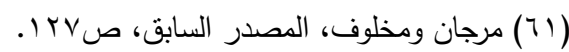

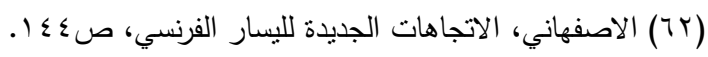

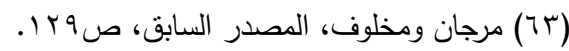

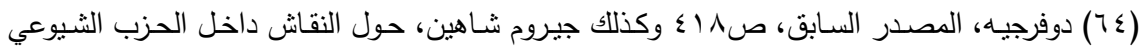

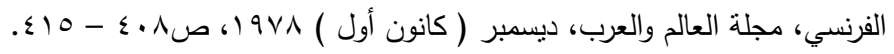

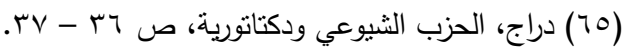

(*)ربيع براغ : حركة نغيير قاده كتاب ومنقفين وأدباء للمطالبـة بحقوق الإنسـان والتعددية الحزبيـة لكن

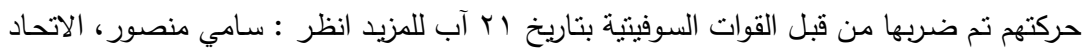

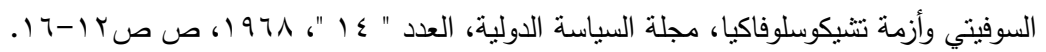

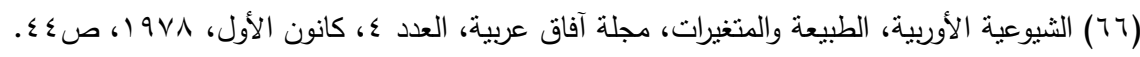

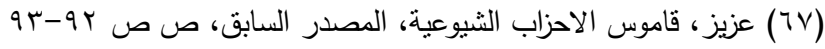

(ヶ^) A.Akoun, Op.Cit, P. 260.

(79) دراج، الحزب الثيوعي ودكتاتورية، المصدر السابق، ص ^ז.

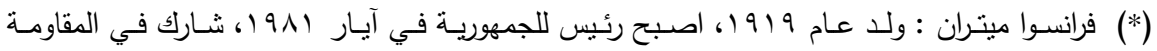

الفرنسية ضد الالمـان وتقلد مناصب اداريـة وزاريـة عديدة ونائبا في مجلس الثيوخ (السينا) لفترات

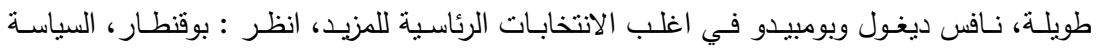

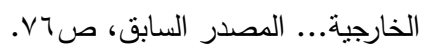

( $•$ •) André, Akown, Op.Cit , P. 60

(v) Ibid, P. 60.

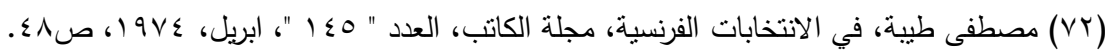

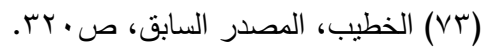

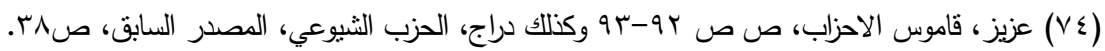

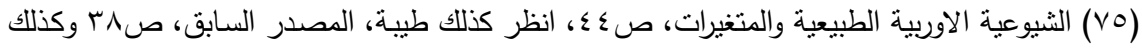

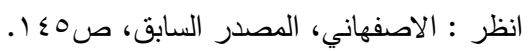

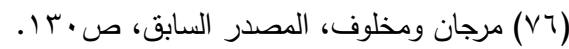

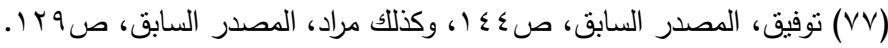

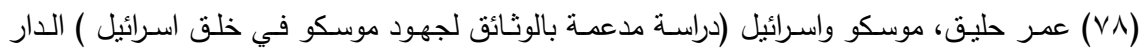

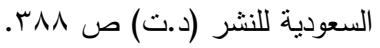


د. أكرم عبد علي ] [ [ 19 [ ] الحزب الثيو عي الفرنسي وموقفه..

$$
\begin{aligned}
& \text { (V9) قدري قلعجي، مناقتشة أراء العلماء والقادة السوفيت وقضية فلسطين، دار الكاتب العربي، (د.ت)، }
\end{aligned}
$$

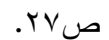

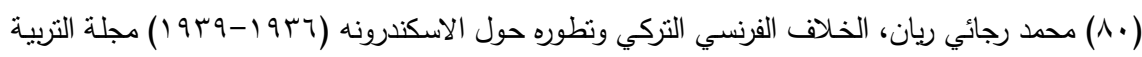

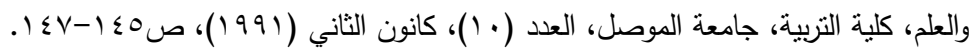

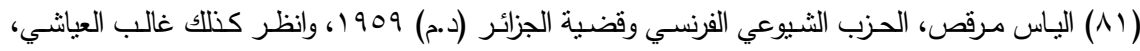

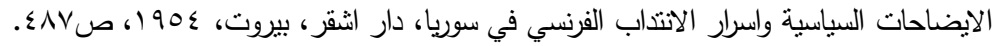

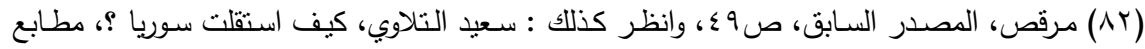

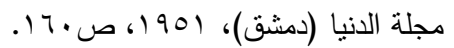

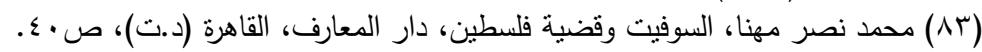

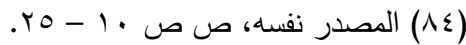

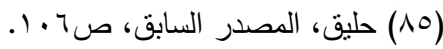

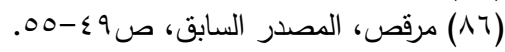

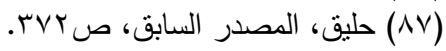

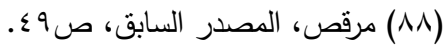

(^9) P. Miquel, Op.Cit, P. 258-259.

(१.) P. Courtier, La Quatrieme République, Conatriém édition, Paris, 1986, P. 97 - 98.

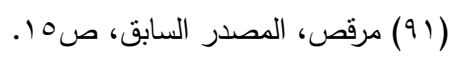

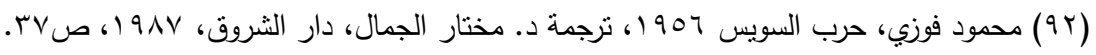

(9 ( ) La Maseillaise, 3 Novembre, 1956.

(१६) Ibid, 6 November 1956.

(90) Ibid , 3 November , 1956.

(१५) Ibid , 30 November, 1956.

(9v) Ibid , 7 December , 1956.

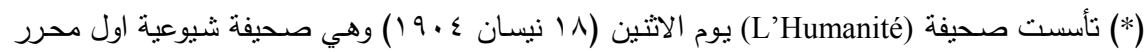

لها (الاشتراكي) جون جوريس واعقبه مارسيل كاثشان، تعبر عن لسان الحزب الثان الثيوعي الفرنسي لحد الحد

$$
\text { الان. للمزيد انظر : الانثراك جرن }
$$

E.Derieux et J. Texcier, La Presse Quotidienne Française, Colin , Paris Ve, Saint Michel , 1974 , P. $84-86$.

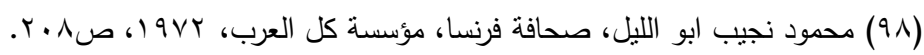

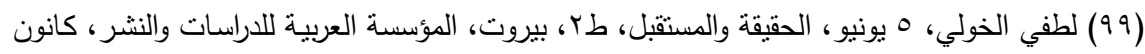

(1...) L'Humanité, 7 Juin , 1967.

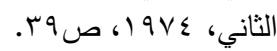

(1. 1) Ibid, 20 Juin , 1967. 
(r + ( ) جاك كوبار ، أوراق جديدة عن حرب الأيام الستة، تعريب نهاد خير، بيروت، دار الفارابي، تشرين

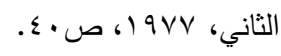

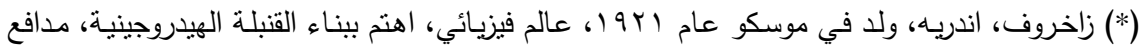

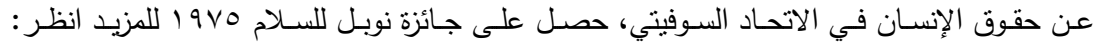
.Encyclopédique, Larousse, Op.Cit , P. 1671

(1.r) L'Humanité, Op.cit, P.7.

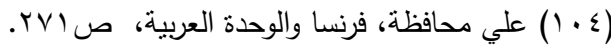

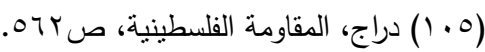

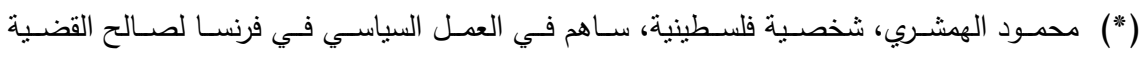

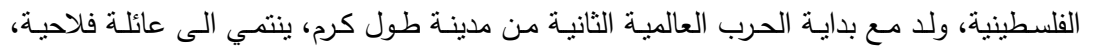

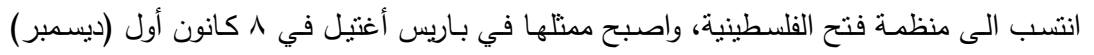

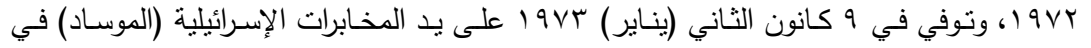

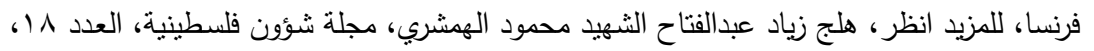

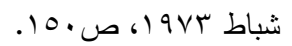

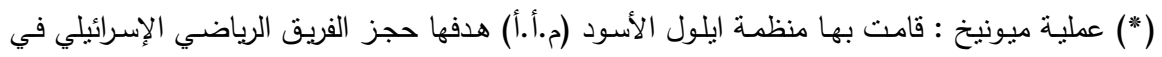

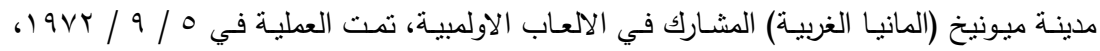

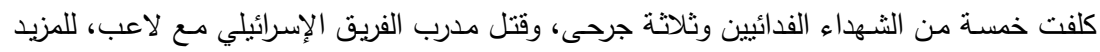

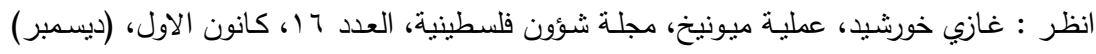

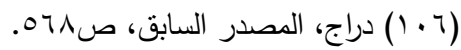

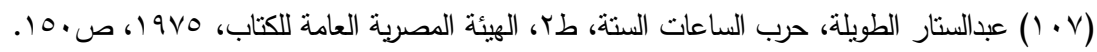

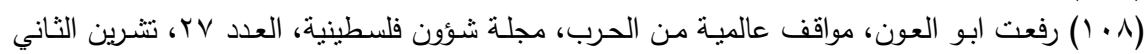

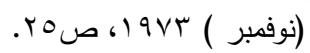

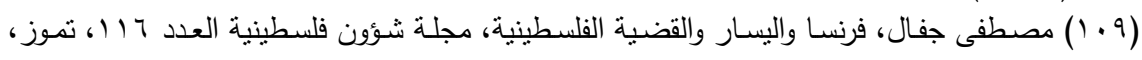

$$
\text { . } 50 \text { ص 61911 }
$$

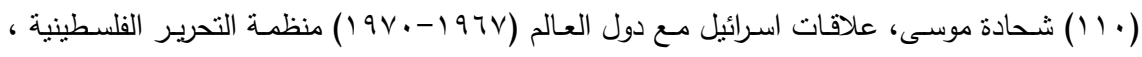

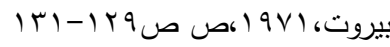

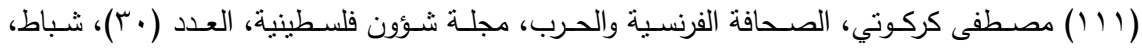

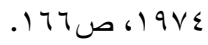

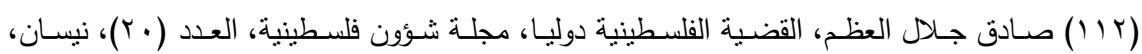

